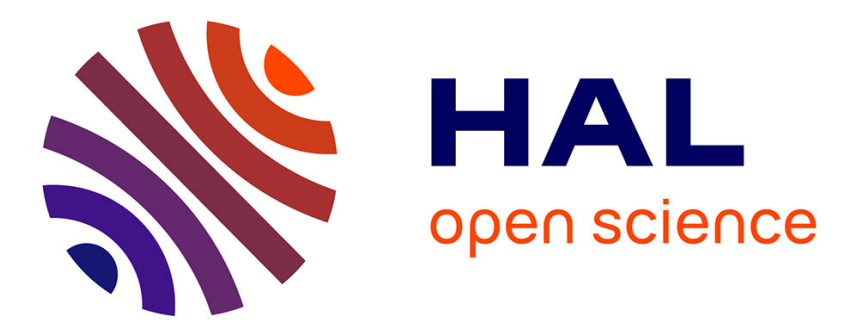

\title{
Synthesis, in vitro antiproliferative activities, and Chk1 inhibitory properties of dipyrrolo[3,4-a:3,4-c]carbazole triones.
}

Elisabeth Conchon, Fabrice Anizon, R. Golsteyn, S. Leonce, Bruno Pfeiffer, Michelle Prudhomme

\section{To cite this version:}

Elisabeth Conchon, Fabrice Anizon, R. Golsteyn, S. Leonce, Bruno Pfeiffer, et al.. Synthesis, in vitro antiproliferative activities, and Chk1 inhibitory properties of dipyrrolo[3,4-a:3,4-c] carbazole triones.. Tetrahedron, 2006, 62, pp.11136-11144. 10.1016/j.tet.2006.09.027 . hal-00119566

\section{HAL Id: hal-00119566 https://hal.science/hal-00119566}

Submitted on 2 Mar 2007

HAL is a multi-disciplinary open access archive for the deposit and dissemination of scientific research documents, whether they are published or not. The documents may come from teaching and research institutions in France or abroad, or from public or private research centers.
L'archive ouverte pluridisciplinaire HAL, est destinée au dépôt et à la diffusion de documents scientifiques de niveau recherche, publiés ou non, émanant des établissements d'enseignement et de recherche français ou étrangers, des laboratoires publics ou privés. 


\title{
Synthesis, in vitro antiproliferative activities, and Chk1 inhibitory properties of dipyrrolo[3,4-a:3,4-c]carbazole-triones
}

\author{
Elisabeth Conchon, ${ }^{\mathrm{a}}$ Fabrice Anizon, ${ }^{\mathrm{a}}$ Roy M. Golsteyn, ${ }^{\mathrm{b}}$ Stéphane Léonce, ${ }^{\mathrm{b}}$ \\ Bruno Pfeiffer ${ }^{\mathrm{b}}$ and Michelle Prudhomme ${ }^{\mathrm{a}, *}$ \\ ${ }^{a}$ Laboratoire SEESIB, Université Blaise Pascal, Clermont Ferrand, UMR 6504 du CNRS, 63177 Aubière Cedex, France \\ bInstitut de Recherches SERVIER, Division Recherche Cancérologie, 125 Chemin de ronde, 78290 Croissy sur Seine, France \\ Received 23 June 2006; revised 5 September 2006; accepted 12 September 2006 \\ Available online 5 October 2006
}

\begin{abstract}
The syntheses of dipyrrolo[3,4- $a: 3,4-c]$ carbazole-1,4,6-triones and dipyrrolo[3,4- $a: 3,4-c]$ carbazole-3,4,6-triones are reported. These compounds can be considered as granulatimide analogues in which a maleimide replaces the imidazole moiety and a five-membered lactam ring replaces the upper maleimide. The Chk1 inhibitory properties of the more soluble compounds have been evaluated and their in vitro antiproliferative activities toward three tumor cell lines: murine leukemia L1210, and human colon carcinoma HT29 and HCT116. Due to their insolubility, the biological activities of the other compounds in this series could not be evaluated. All the tested compounds proved to be potent Chk1 inhibitors.
\end{abstract}

(C) 2006 Elsevier Ltd. All rights reserved.

\section{Introduction}

The carbazole framework is found in many biologically active compounds. Some of them, such as rebeccamycin, are topoisomerase I inhibitors. Others, such as staurosporine and UCN-01, are inhibitors of kinases. ${ }^{1-3}$ Granulatimide and isogranulatimide, natural compounds isolated from an ascidian, as well as staurosporine and UCN-01, indolocarbazole compounds isolated from cultures of Streptomyces, or synthetic compounds such as SB-218078 have triggered considerable interest as cell cycle G2 checkpoint inhibitors (Fig. 1). ${ }^{4-7}$ In the cell division cycle, the G2 checkpoint is activated in response to DNA damage. Its role consists in blocking the cell cycle to allow time for DNA repair. In more than $60 \%$ of cancer cells, the G1 checkpoint is lacking, due to mutations of the $p 53$ gene. In the p53-mutated cells, only the G2 ckeckpoint provides cancer cells with an opportunity to repair their DNA after damage. Accordingly, combining a DNA damaging agent with a G2 checkpoint inhibitor will force selectively cancer cells into a premature and lethal mitosis due to an accumulation of DNA lesions. ${ }^{8-10}$ The Chk1 kinase plays a major role in the G2 checkpoint regulation. ${ }^{11,12}$ Therefore, Chk1 inhibitors are relevant targets for the conception of agents that are able

Keywords: Granulatimide; Dipyrrolo[3,4- $a: 3,4-c]$ carbazole-1,4,6-trione; Dipyrrolo[3,4-a:3,4-c]carbazole-3,4,6-trione; Antitumor agents; Chk1 inhibitors.

* Corresponding author. Tel.: +33 47340 7124; fax: +33 473407717 ; e-mail: michelle.prudhomme@univ-bpclermont.fr to kill selectively cancer cells without causing damage to healthy cells. Granulatimide, isogranulatimide, staurosporine, UCN-01, and SB-218078 were found to be efficient Chk1 inhibitors. All of them possess a carbazole moiety, with an upper heterocycle containing an imide or a lactam function. Moreover, in staurosporine, UCN-01, and SB218078 , a carbohydrate-like heterocycle is linked to both indole nitrogens.

The crystal structures of SB-218078, staurosporine, UCN$01,{ }^{13}$ and isogranulatimide ${ }^{14}$ in complex with Chk 1 kinase, have been determined. These compounds are ATP-competitive Chk 1 inhibitors. In the structures of the four complexes,
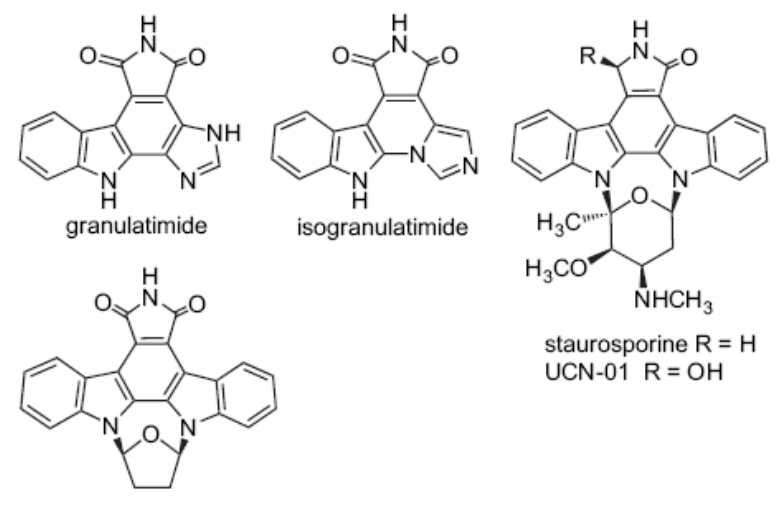

staurosporine $\mathrm{R}=\mathrm{H}$ $\mathrm{UCN}-01 \mathrm{R}=\mathrm{OH}$
SB-218078

Figure 1. 


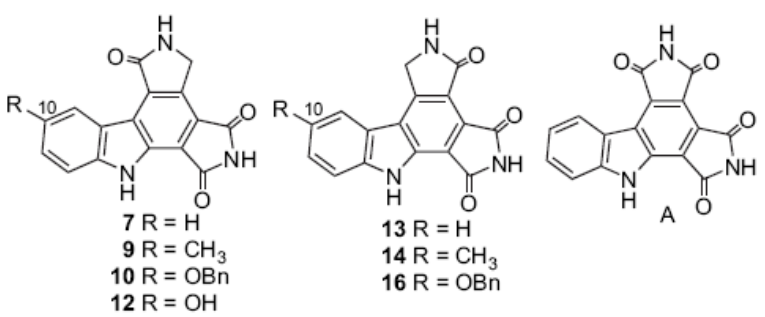

Figure 2.

two hydrogen bonds between the inhibitors and the ATP binding site of the enzyme are conserved: the first one between the NH of the upper heterocycle and the carbonyl oxygen of $\mathrm{Glu}^{85}$, and the second one between the oxygen of the carbonyl group of the lactam or imide function of the drug and the amide nitrogen of $\mathrm{Cys}^{87}$. Granulatimide and isogranulatimide isomers, and structurally related compounds bearing modified heterocycles, have been recently synthesized. $^{15-24}$

In this paper, we describe the syntheses of dipyrrolo[3,4- $a$ : $3,4-c$ carbazole-1,4,6-triones and dipyrrolo $[3,4-a: 3,4-c]$ carbazole-3,4,6-triones (Fig. 2). Compared with granulatimide and isogranulatimide, the imidazole has been replaced by a maleimide and the upper heterocycle contains a lactam function, like in staurosporine, instead of the imide function present in granulatimide and isogranulatimide. Moreover, several substituents have been introduced in the 10-position of the indole moiety. Some compounds in this series proved to be extremely insoluble, therefore, their biological activities could not be evaluated. For the most soluble compounds, the Chk 1 inhibitory activities and the cytotoxicities toward three tumor cell lines: murine leukemia L1210, and human colon carcinoma HT29 and HCT116 were evaluated.

\section{Results and discussion}

\subsection{Chemistry}

In previous works, ${ }^{22-24}$ we described the four-step synthesis of bis-imides granulatimide analogues (Scheme 1). A similar synthetic scheme was applied for the synthesis of

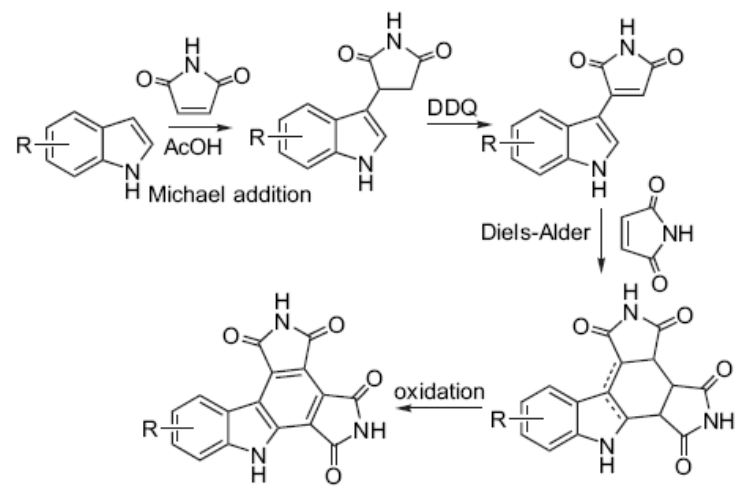

Scheme 1.

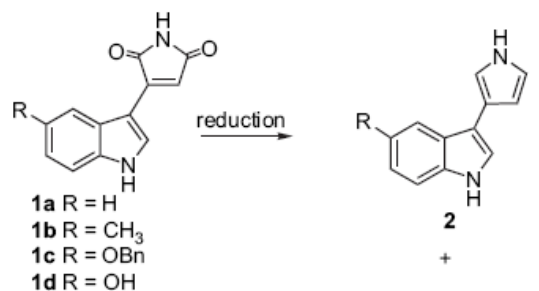

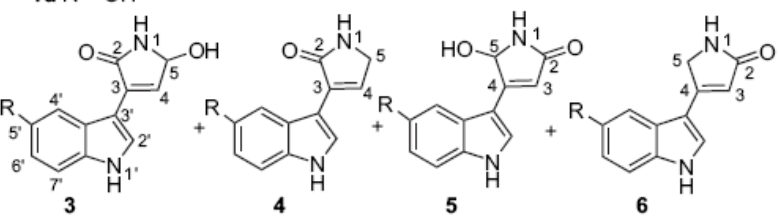

Scheme 2.

dipyrrolo[3,4- $a: 3,4-c]$ carbazole-triones. The reduction of the 3-(indol-3-yl)-maleimides intermediates led to lactams and hydroxylactams, from which the synthesis was completed.

Hydroxy and methyl substituents were introduced in the 10position because in the bis-imide series, these substitutions led to the most efficient Chk 1 inhibitors.

3-(Indol-3-yl)-maleimides 1a-d $\left(\mathrm{R}=\mathrm{H}, \mathrm{OBn}, \mathrm{OH}\right.$, and $\left.\mathrm{CH}_{3}\right)$ were prepared as previously described ${ }^{22,24}$ in two steps from the corresponding substituted indoles via a Michael addition with maleimide followed by dehydrogenation of the Michael adduct using DDQ. The corresponding lactams and hydroxylactams were obtained by reduction of the 3-(indol-3-yl)maleimides (Scheme 2).

Depending on the reducing agent $\left(\mathrm{LiAlH}_{4}, \mathrm{NaBH}_{4}\right.$ or DIBAL-H) and the substituent on the indole moiety, important variations were observed in the yields of compounds 2-6 (Table 1). Indeed, Mase et al. ${ }^{25}$ showed that the regioselectivity of the reduction of monosubstituted maleimides using $\mathrm{NaBH}_{4}$ was due to the approach of the hydride anion from the less hindered carbonyl group. Therefore, the hydride anion attacks the more hindered carbonyl group. When using DIBAL-H, the inverted regioselectivity is explained by the complexation effect of the carbonyl group with an aluminum atom preferably coordinated to the less hindered carbonyl group. Therefore, the hydride anion approaches from the more hindered carbonyl group and attacks

Table 1. Percentages of compounds $2,3,4,5$, and 6 obtained by reduction of 1a-d using $\mathrm{LiAlH}_{4}, \mathrm{NaBH}_{4}$ or DIBAL-H and ratio for the reductions on $\mathrm{Cl}$ / $\mathrm{Cm}$ ( $\mathrm{Cl}$ : less hindered carbon, $\mathrm{Cm}$ : more hindered carbon)

\begin{tabular}{|c|c|c|c|c|c|c|c|c|}
\hline \multirow{2}{*}{$\begin{array}{l}\text { Starting } \\
\text { product }\end{array}$} & \multirow{2}{*}{$\begin{array}{l}\text { Reducing } \\
\text { agent }\end{array}$} & \multicolumn{5}{|c|}{ Compounds (\%) } & \multirow{2}{*}{\multicolumn{2}{|c|}{$\begin{array}{l}\text { Reduction ratio } \\
\text { on } \mathrm{Cl} / \mathrm{Cm}(\%)\end{array}$}} \\
\hline & & 2 & 3 & 4 & 5 & 6 & & \\
\hline \multirow[t]{3}{*}{$1 \mathrm{a}$} & $\mathrm{LiAlH}_{4}$ & 9 & 6 & 11 & 23 & 19 & 29 & 71 \\
\hline & $\mathrm{NaBH}_{4}$ & 0 & 11 & 0 & 60 & 0 & 16 & 84 \\
\hline & DIBAL-H & 0 & 17 & 33 & 15 & 0 & 77 & 23 \\
\hline \multirow[t]{2}{*}{$1 b$} & $\mathrm{LiAlH}_{4}$ & 1 & 0 & 11 & 17 & 21 & 22 & 78 \\
\hline & DIBAL-H & 0 & 54 & 11 & 19 & 0 & 78 & 22 \\
\hline \multirow[t]{2}{*}{$1 \mathrm{c}$} & $\mathrm{LiAlH}_{4}$ & 0 & 0 & 6 & 24 & 40 & 8 & 92 \\
\hline & DIBAL-H & 0 & 42 & 13 & 13 & 0 & 81 & 19 \\
\hline \multirow[t]{2}{*}{ 1d } & $\mathrm{LiAlH}_{4}$ & 0 & 0 & 12 & 33 & 0 & 27 & 73 \\
\hline & DIBAL-H & 0 & 0 & 28 & 15 & 0 & 65 & 35 \\
\hline
\end{tabular}


the less hindered carbonyl group (Scheme 3 ). In compounds 3 and $\mathbf{4}$, the less hindered carbonyl group has been reduced, whereas in compounds $\mathbf{5}$ and $\mathbf{6}$, the more hindered carbonyl group has been reduced. With the less bulky $\mathrm{LiAlH}_{4}$, the complexation of both carbonyl groups with an aluminum atom may occur, but the hydride anion approaches very probably more quickly from the less hindered side. The structure of compounds $\mathbf{4 a}$ was assigned from NMR NOESY correlations between the two methylene protons and the $\mathrm{NH}$ of the lactam function and the vicinal ethylenic proton (Scheme 4). In compound 6a, no NOESY correlations were observed between the protons of the methylene group and the ethylenic proton. The $\mathrm{H}_{4}$ of compound $\mathbf{4 a}$ is shifted at $7.43 \mathrm{ppm}$, whereas the $\mathrm{H}_{3}$ of compound $\mathbf{6 a}$ is shifted at $6.26 \mathrm{ppm}$. Based on these NMR data, the structures of compounds $\mathbf{3 a}$ and $\mathbf{5} \mathbf{a}$ were assigned $\left(\mathbf{3} \mathbf{a}: \mathrm{H}_{4}\right.$ at $7.14 \mathrm{ppm}, \mathbf{5} \mathbf{a}: \mathrm{H}_{3}$ at $6.17 \mathrm{ppm}$ ). By analogy with the unsubstituted compounds 3a-6a, the structures of the analogues substituted in $5^{\prime}$-position on the indole moiety were assigned from the chemical shifts of the ethylenic protons.

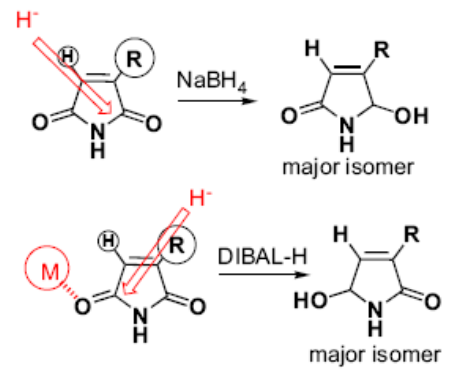

Scheme 3.

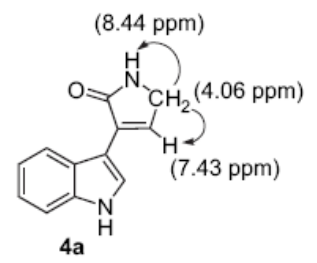

Scheme 4 .

The next step was a Diels-Alder cycloaddition with maleimide. In previous studies, it was observed that the DielsAlder cycloaddition carried out between 3 -indolyl-maleimide and maleimide could lead, according to the treatment, filtration or chromatography on silicagel, to indoline or indole isomers. ${ }^{22,26}$ When the Diels-Alder reaction was performed from $\mathbf{4 a}$ and $\mathbf{4 c}$, the mixture of isomers could not be separated. The oxidation yielding to the final aromatic compounds 7 and $\mathbf{1 0}$ was carried out on the isomeric mixture. With lactams $\mathbf{4 b}$ and $\mathbf{4 d}$, the indole intermediate $\mathbf{8}$ and the indoline intermediate $\mathbf{1 1}$ were isolated. The position of the double bond was determined from ${ }^{1} \mathrm{H}$ NMR data. Indeed, an indole and an imide $\mathrm{NH}$ are usually shifted at about 11-12 ppm, whereas an indoline and a lactam $\mathrm{NH}$ are shifted at about 7-9 ppm. In compounds 8, two exchangeable protons are shifted at 11.12 , and $11.52 \mathrm{ppm}$ whereas in compound 11, only one exchangeable proton was shifted at $10.94 \mathrm{ppm}$. Oxidation of the intermediates in dioxane in

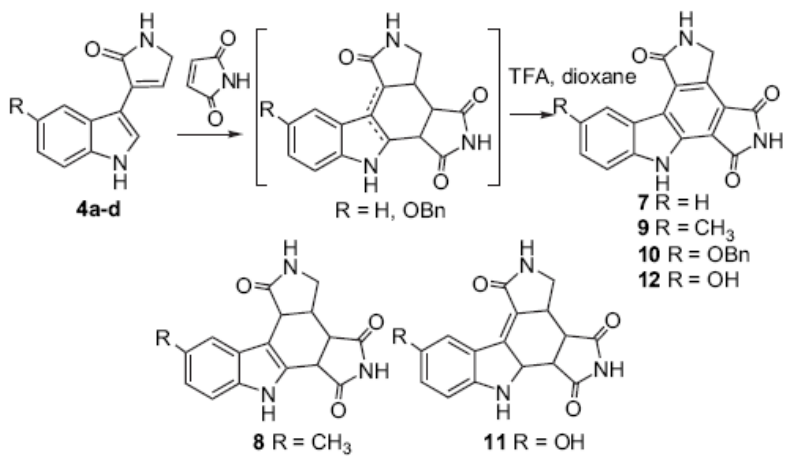<smiles>[R]c1ccc2[nH]cc(C3=CC(=O)NC3O)c2c1</smiles>

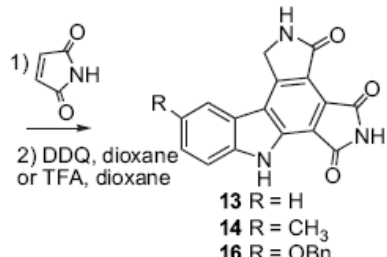

$14 \mathrm{R}=\mathrm{CH}_{3}$<smiles>[Y6][Y4](=O)O[B]</smiles>

Scheme 5.

the presence of TFA gave lactams 7, 9, 10, and 12 (Scheme 5).

Diels-Alder reactions performed from hydroxy-lactams 3a-d did not lead to the cycloadducts, whereas from hydroxy-lactams 5a-d, the cycloaddition occurred with the loss of a water molecule. With compounds $\mathbf{5} \mathbf{c}$ and $\mathbf{5 d}$, the indole intermediates 15 and $\mathbf{1 7}$ could be isolated. Oxidation of the intermediates in dioxane, either in the presence of TFA or with DDQ, led to the required lactams 13,14 , and 16. In spite of various modifications of the oxidation procedure of intermediate 17 (in dioxane in the presence of TFA from 6 to 20 equiv from $60{ }^{\circ} \mathrm{C}$ to $80^{\circ} \mathrm{C}$ or with DDQ 2 equiv in dioxane at room temperature), the required aromatized compound could not be obtained. Concomitant with the aromatization, oxidation of the lactam heterocycle to imide was observed.

Cycloadditions between maleimide and lactams 6 did not lead to the required cycloadducts. With lactam $\mathbf{6}$ in which $\mathrm{R}=\mathrm{H}$, depending on the solvents used, either a double Diels-Alder reaction or a Diels-Alder reaction followed by a Michael addition with a second molecule of maleimide occurred.

\subsection{Chk1 inhibitory activities}

The Chk1 inhibitory activities could only be determined with compounds $7,10,12,13$, and intermediate 17 and were compared with those of granulatimide, isogranulatimide, and bis-imide analogue A (Fig. 2) (Table 2). ${ }^{27}$ Due 
Table 2. Percentages of Chk1 inhibition at a drug concentration of $10 \mu \mathrm{M}$, $\mathrm{IC}_{50}$ values $(\mu \mathrm{M})$ toward Chk1; in vitro antiproliferative activities against three tumor cell lines: murine leukemia L1210, and human HT29 and HCT116 colon carcinoma $\left(\mathrm{IC}_{50} \mu \mathrm{M}\right)$

\begin{tabular}{llllll}
\hline Compound & $\begin{array}{l}\text { \% of Chk1 } \\
\text { inhibition } \\
\text { at } 10 \mu \mathrm{M}\end{array}$ & $\begin{array}{l}\mathrm{IC}_{50} \\
\text { Chk1 } \\
(\mu \mathrm{M})\end{array}$ & L1210 & HCT116 & HT29 \\
\hline Granulatimide & 93.9 & 0.08 & 2.8 & 6.1 & 5.7 \\
Isogranulatimide & 89.7 & 0.44 & 10 & 13 & 13.7 \\
$\mathbf{A}$ & 94.4 & 0.02 & 32.7 & nd & 9.7 \\
$\mathbf{7}$ & 85.4 & 0.05 & nd & nd & nd \\
$\mathbf{1 0}$ & 69.8 & 1 & 25.9 & 28.3 & 36.4 \\
$\mathbf{1 2}$ & 95.7 & 0.01 & 54.5 & 63.5 & 41.8 \\
$\mathbf{1 3}$ & 71.7 & 0.37 & 47.0 & 58.9 & $>100$ \\
$\mathbf{1 7}$ & 78.6 & 2.83 & $>50$ & 43.7 & 49.7 \\
\hline
\end{tabular}

to the insolubility of compounds $\mathbf{9 , 1 4}$, and $\mathbf{1 6}$, their Chk 1 inhibitory activities could not be evaluated. Compounds $\mathbf{7}$, unsubstituted at the 10-position, and compound 12 bearing a hydroxy group, are stronger Chk 1 inhibitors than granulatimide and isogranulatimide. Interestingly, when the carbonyl of the lactam heterocycle is oriented toward the indole moiety, the compounds seem to be more efficient Chk1 inhibitors than those in which the carbonyl of the lactam heterocycle is oriented toward the imide heterocycle (compare 7 and 13). These results are not completely surprising since, in the crystal structures of staurosporine, $\mathrm{UCN}-01$, and isogranulatimide in complex with Chk1, the carbonyl on the left of the upper heterocycle accepts a hydrogen bond from the amide nitrogen of $\mathrm{Cys}^{87}$, whereas no hydrogen bond is formed with the carbonyl located on the right. However, the strong Chk1 inhibitory activity of compound $\mathbf{1 3}$ could be due to a different position of the molecule in the ATP binding site allowing the formation of the two fundamental hydrogen bonds with $\mathrm{Glu}^{85}$ and $\mathrm{Cys}^{87}$. In this orientation, the imide heterocycle would be positioned on the left and the indole moiety would lie on the right. No significant differences are observed between the Chk1 inhibitory activities of lactam 7 and imide A. Compared with unsubstituted compound $\mathbf{7}$, compound $\mathbf{1 2}$ substituted with a hydroxy group is a stronger Chk1 inhibitor.

\subsection{In vitro antiproliferative activities}

The cytotoxicities of the soluble compounds were evaluated toward three tumor cell lines: murine leukemia L1210, and human colon carcinoma HT29 and HCT116 and compared with those of granulatimide, isogranulatimide, and compound A (Table 2). Compared with granulatimide and isogranulatimide, all the lactams tested are considerably less active, their cytotoxicities are in the same range as those of imide A. A checkpoint inhibitor is not expected to be cytotoxic by itself. However, the weak in vitro antiproliferative activities of the new compounds described in this paper suggests a possible instability of these compounds in the biological medium.

\section{Conclusion}

In conclusion, this work reports the synthesis of pyrrolo[3,4$a: 3,4-c]$ carbazole-1,4,6-tetraones and pyrrolo[3,4- $a: 3,4-c]$ carbazole-3,4,6-tetraones. These compounds are structurally related to the Chk1 inhibitor granulatimide. Their upper heterocycle contains a lactam function like in staurosporine. All the new compounds are potent Chk1 inhibitors suggesting that the orientation of the carbonyl group of the upper heterocycle, either toward the indole moiety or toward the maleimide unit, could modify the positioning of the drug in the active site of the kinase. Their weak cytotoxicity could be due to a limited penetration into the cells or to a degradation in the biological media. This hypothesis is currently under investigation.

\section{Experimental}

\subsection{Chemistry}

IR spectra were recorded on a Perkin-Elmer 881 spectrometer $\left(\nu\right.$ in $\left.\mathrm{cm}^{-1}\right)$. NMR spectra were performed on a Bruker AVANCE 400 and AVANCE 500 (chemical shifts $\delta$ in parts per million, the following abbreviations are used: singlet (s), broad singlet (br s), doublet (d), doubled doublet (dd), triplet $(\mathrm{t})$, doubled triplet $(\mathrm{dt})$, multiplet $(\mathrm{m})$, pseudo quadruplet (pq), tertiary carbons (C tert), and quaternary carbons (C quat). The signals were assigned from ${ }^{1} \mathrm{H}-{ }^{1} \mathrm{H}$ COSY, HSQC, and HMBC NMR correlations. Low-resolution mass spectra (ESI+ and APCI+) and HRMS were determined on a MS Hewlett Packard instrument. Chromatographic purifications were performed by flash silicagel Geduran SI 60 (Merck) 0.040-0.063 mm column chromatography.

\subsection{Typical procedure for the reduction using $\mathrm{LiAlH}_{4}$}

To a solution of 3-(indol-3-yl)-maleimide (200 mg, $0.94 \mathrm{mmol})$ in THF $(40 \mathrm{~mL}$ ) was added dropwise a $1 \mathrm{M}$ solution of $\mathrm{LiAlH}_{4}$ in $\mathrm{Et}_{2} \mathrm{O}(6 \mathrm{~mL})$ at room temperature. The mixture was stirred for 3 days. After cooling to $0{ }^{\circ} \mathrm{C}$, water $(14 \mathrm{~mL})$ was added. The mixture was acidified to $\mathrm{pH} 2$ with $2 \mathrm{M} \mathrm{HCl}(2 \mathrm{~mL})$. After extraction with EtOAc, the organic phase was washed with saturated aqueous $\mathrm{NaHCO}_{3}$. The organic phase was dried over $\mathrm{MgSO}_{4}$ and the solvent was removed. The residue was purified by flash chromatography (eluent: from EtOAc/cyclohexane 1:1 to EtOAc/MeOH 9:1).

\subsection{Typical procedure for the reduction using $\mathrm{NaBH}_{4}$}

To a solution of 3-(indol-3-yl)-maleimide $(2.4 \mathrm{mmol})$ in THF $(50 \mathrm{~mL})$ was added sodium borohydride $(90 \mathrm{mg}$, $2.4 \mathrm{mmol}$ ) in portions. The mixture was stirred at room temperature for $24 \mathrm{~h}$. After cooling to $0{ }^{\circ} \mathrm{C}$, water was added. After extraction with EtOAc, the organic phase was dried over $\mathrm{MgSO}_{4}$, the solvent was removed and the residue was purified by flash chromatography (eluent: from cyclohexane/EtOAc 1:1 to EtOAc/MeOH 9:1).

\subsection{Typical procedure for the reduction using DIBAL-H}

To a solution of 3-(indol-3-yl)-maleimide $(0.94 \mathrm{mmol})$ in THF $(70 \mathrm{~mL})$ at $-78^{\circ} \mathrm{C}$ was added dropwise a $1 \mathrm{M}$ solution of DIBAL-H in toluene $(2.3 \mathrm{~mL})$. The mixture was stirred for $1.5 \mathrm{~h}$ at $-78^{\circ} \mathrm{C}$, then a $1 \mathrm{M}$ solution of DIBAL-H in toluene $(2.3 \mathrm{~mL})$ was added. The mixture was stirred at $-78^{\circ} \mathrm{C}$ for $6 \mathrm{~h}$. Then the mixture was warmed to $0{ }^{\circ} \mathrm{C}$ and saturated aqueous $\mathrm{NaHCO}_{3}$ was added dropwise. After extraction 
with EtOAc, the organic phase was dried over $\mathrm{MgSO}_{4}$, the solvent was removed and the residue was purified by flash chromatography (eluent: from EtOAc/cyclohexane 1:1 to $\mathrm{EtOAc/MeOH} \mathrm{9:1).}$

4.4.1. 3-(1H-Indol-3-yl)- $\boldsymbol{H} \boldsymbol{H}$-pyrrole (2a). Yellow solid. Mp $65^{\circ} \mathrm{C}$. IR $(\mathrm{KBr}) \nu_{\mathrm{NH}} 2924 \mathrm{~cm}^{-1}$. HRMS (ESI+) $[\mathrm{M}+\mathrm{H}]^{+}$ calcd for $\mathrm{C}_{12} \mathrm{H}_{11} \mathrm{~N}_{2}$ 183.0922, found 183.0926.

${ }^{1} \mathrm{H}$ NMR (400 MHz, DMSO- $\left.d_{6}\right): 6.38(1 \mathrm{H}, \mathrm{s}), 6.79(1 \mathrm{H}, \mathrm{s})$, $7.04\left(1 \mathrm{H}, \mathrm{dt}, J_{1}=7.0 \mathrm{~Hz}, J_{2}=1.0 \mathrm{~Hz}\right), 7.09-7.10(2 \mathrm{H}, \mathrm{m})$, $7.37(1 \mathrm{H}, \mathrm{d}, J=8.0 \mathrm{~Hz}), 7.40(1 \mathrm{H}, \mathrm{d}, J=2.5 \mathrm{~Hz}), 7.77(1 \mathrm{H}$, d, $J=8.0 \mathrm{~Hz}), 10.73(1 \mathrm{H}$, br s), $10.91(1 \mathrm{H}, \mathrm{s})$.

${ }^{13} \mathrm{C}$ NMR (100 MHz, DMSO- $\left.d_{6}\right): 106.1,111.4,113.4$, $117.8,118.5,119.5,120.6,120.8$ (C tert), 111.6, 117.4, $125.4,136.5$ (C quat).

4.4.2. 3-(1H-Indol-3-yl)-1H-5-hydroxy-2,5-dihydro-pyrrol-2-one (3a). Orange-brown solid. $\mathrm{Mp}>300{ }^{\circ} \mathrm{C}$. IR $(\mathrm{KBr}) \nu_{\mathrm{C}=\mathrm{C}} 1632 \mathrm{~cm}^{-1}, \nu_{\mathrm{C}=\mathrm{O}} 1705 \mathrm{~cm}^{-1}, \nu_{\mathrm{NH}-\mathrm{OH}} 3200-$ $3500 \mathrm{~cm}^{-1}$. Mass (ESI+) $[\mathrm{M}+\mathrm{Na}]^{+} 237$.

${ }^{1} \mathrm{H}$ NMR $\left(400 \mathrm{MHz}\right.$, DMSO- $\left.d_{6}\right): 5.59(1 \mathrm{H}, \mathrm{d}, J=9.0 \mathrm{~Hz}$, $\left.\mathrm{H}_{5}\right), 5.99(1 \mathrm{H}, \mathrm{d}, J=9.0 \mathrm{~Hz}, \mathrm{OH}), 7.14\left(1 \mathrm{H}, \mathrm{s}, \mathrm{H}_{4}\right), 7.18$ $\left(1 \mathrm{H}, \mathrm{dt}, J_{1}=8.0 \mathrm{~Hz}, J_{2}=1.0 \mathrm{~Hz}\right), 7.21\left(1 \mathrm{H}, \mathrm{dt}, J_{1}=8.0 \mathrm{~Hz}\right.$, $\left.J_{2}=1.0 \mathrm{~Hz}\right), \quad 7.51 \quad(1 \mathrm{H}, \quad \mathrm{d}, \quad J=8.0 \mathrm{~Hz}), 7.94 \quad(1 \mathrm{H}, \quad \mathrm{d}$, $J=8.0 \mathrm{~Hz}), 8.28(1 \mathrm{H}, \mathrm{d}, J=2.5 \mathrm{~Hz}), 8.65(1 \mathrm{H}, \mathrm{s}), 11.46$ $(1 \mathrm{H}, \mathrm{s})$.

${ }^{13} \mathrm{C}$ NMR (100 MHz, DMSO- $\left.d_{6}\right): 78.2(\mathrm{CHOH}), 106.0$, 125.5, 130.6, 136.1 (C quat), 112.0, 119.7, 119.9, 121.7, $126.5,133.8(\mathrm{C}$ tert $), 171.7(\mathrm{C}=\mathrm{O})$.

4.4.3. 3-(1H-Indol-3-yl)-1H-2,5-dihydro-pyrrol-2-one (4a). Orange-brown solid. Mp 205-207 ${ }^{\circ} \mathrm{C}$. IR (KBr) $\nu_{\mathrm{C}=\mathrm{C}}$ $1628 \mathrm{~cm}^{-1}, \nu_{\mathrm{C}=\mathrm{O}} 1678 \mathrm{~cm}^{-1}, \nu_{\mathrm{NH}} 3284 \mathrm{~cm}^{-1}$. HRMS (ESI+) $[\mathrm{M}+\mathrm{H}]^{+}$calcd for $\mathrm{C}_{12} \mathrm{H}_{11} \mathrm{~N}_{2} \mathrm{O}$ 199.0871, found 199.0880.

${ }^{1} \mathrm{H}$ NMR (400 MHz, DMSO- $\left.d_{6}\right): 4.06\left(2 \mathrm{H}, \mathrm{s}, \mathrm{CH}_{2}\right), 7.15$ $\left(1 \mathrm{H}, \quad \mathrm{dt}, \quad J_{1}=8.0 \mathrm{~Hz}, \quad J_{2}=1.0 \mathrm{~Hz}, \mathrm{H}_{5^{\prime}}\right), 7.24(1 \mathrm{H}, \mathrm{dt}$, $\left.J_{1}=8.0 \mathrm{~Hz}, J_{2}=1.0 \mathrm{~Hz}, \mathrm{H}_{6^{\prime}}\right), 7.43\left(1 \mathrm{H}, \mathrm{d}, J=1.5 \mathrm{~Hz}, \mathrm{H}_{4}\right)$, $7.49\left(1 \mathrm{H}, \mathrm{d}, J=8.0 \mathrm{~Hz}, \mathrm{H}_{7^{\prime}}\right), 7.93\left(1 \mathrm{H}, \mathrm{d}, J=8.0 \mathrm{~Hz}, \mathrm{H}_{4^{\prime}}\right)$, $8.28\left(1 \mathrm{H}, \mathrm{d}, J=2.5 \mathrm{~Hz}, \mathrm{H}_{2^{\prime}}\right), 8.44\left(1 \mathrm{H}, \mathrm{s}, \mathrm{NH}_{1}\right), 11.36(1 \mathrm{H}$, $\left.\mathrm{s}, \mathrm{NH}_{\text {indole }}\right)$.

${ }^{13} \mathrm{C}$ NMR (100 MHz, DMSO- $\left.d_{6}\right): 46.0\left(\mathrm{CH}_{2}\right), 106.8,125.5$ (C quat), 130.6, 136.0 (C quat), 111.8, 119.3, 119.6, 121.5, $125.5(\mathrm{C}$ tert arom), $131.8(\mathrm{CH}$ lactam $), 173.1(\mathrm{C}=\mathrm{O})$.

4.4.4. 4-(1H-Indol-3-yl)-1H-5-hydroxy-2,5-dihydro-pyrrol-2-one (5a). Orange-brown solid. Mp $207{ }^{\circ} \mathrm{C}$. IR (KBr) $\nu_{\mathrm{C}=\mathrm{C}} 1608 \mathrm{~cm}^{-1}, \quad \nu_{\mathrm{C}=\mathrm{O}} 1662 \mathrm{~cm}^{-1}, \quad \nu_{\mathrm{NH}} 3271 \mathrm{~cm}^{-1}$. HRMS (ESI-) $[\mathrm{M}-\mathrm{H}]^{-}$calcd for $\mathrm{C}_{12} \mathrm{H}_{9} \mathrm{~N}_{2} \mathrm{O}_{2}$ 213.0664, found 213.0667 .

${ }^{1} \mathrm{H}$ NMR (400 MHz, DMSO- $\left.d_{6}\right): 5.80\left(1 \mathrm{H}, \mathrm{dd}, J_{1}=9.5 \mathrm{~Hz}\right.$, $\left.J_{2}=1.0 \mathrm{~Hz}, \mathrm{H}_{5}\right), 6.17\left(1 \mathrm{H}, \mathrm{d}, J=1.0 \mathrm{~Hz}, \mathrm{H}_{3}\right), 6.22(1 \mathrm{H}, \mathrm{d}$, $J=9.5 \mathrm{~Hz}, \mathrm{OH}), 7.17\left(1 \mathrm{H}, \mathrm{dt}, J_{1}=8.0 \mathrm{~Hz}, J_{2}=1.0 \mathrm{~Hz}\right), 7.19$ $\left(1 \mathrm{H}, \mathrm{dt}, J_{1}=8.0 \mathrm{~Hz}, J_{2}=1.0 \mathrm{~Hz}\right), 7.47(1 \mathrm{H}, \mathrm{d}, J=8.0 \mathrm{~Hz})$, $7.84(1 \mathrm{H}, \mathrm{d}, J=3.0 \mathrm{~Hz}), 7.85(1 \mathrm{H}, \mathrm{d}, J=8.0 \mathrm{~Hz}), 8.16(1 \mathrm{H}$, s), $11.69(1 \mathrm{H}, \mathrm{s})$.
${ }^{13} \mathrm{C}$ NMR (100 MHz, DMSO- $\left.d_{6}\right): 80.5(\mathrm{CHOH}), 108.0$, 125.3, 136.6, 154.4 (C quat), 112.1, 113.2, 120.1, 120.6, 122.1, 128.5 (C tert), $172.8(\mathrm{C}=\mathrm{O})$.

4.4.5. 4-(1H-Indol-3-yl)-1H-2,5-dihydro-pyrrol-2-one (6a). Brown solid. Mp $255^{\circ} \mathrm{C}$. IR $(\mathrm{KBr}) \nu_{\mathrm{C}=\mathrm{C}} 1610 \mathrm{~cm}^{-1}$, $\nu_{\mathrm{C}=\mathrm{O}} \quad 1649 \mathrm{~cm}^{-1}, \quad \nu_{\mathrm{NH}} 3255 \mathrm{~cm}^{-1}$. HRMS (ESI-) $[\mathrm{M}-\mathrm{H}]^{-}$calcd for $\mathrm{C}_{12} \mathrm{H}_{9} \mathrm{~N}_{2} \mathrm{O} 197.0715$, found 197.0722.

${ }^{1} \mathrm{H}$ NMR (400 MHz, DMSO- $\left.d_{6}\right): 4.42\left(2 \mathrm{H}, \mathrm{s}, \mathrm{CH}_{2}\right), 6.26$ $\left(1 \mathrm{H}, \quad \mathrm{d}, \quad J=1.0 \mathrm{~Hz}, \mathrm{H}_{3}\right), \quad 7.15 \quad\left(1 \mathrm{H}, \quad \mathrm{dt}, \quad J_{1}=8.0 \mathrm{~Hz}\right.$, $\left.J_{2}=1.0 \mathrm{~Hz}, \mathrm{H}_{5^{\prime}}\right), 7.19\left(1 \mathrm{H}, \mathrm{dt}, J_{1}=8.0 \mathrm{~Hz}, J_{2}=1.0 \mathrm{~Hz}, \mathrm{H}_{6^{\prime}}\right)$, $7.46\left(1 \mathrm{H}, \mathrm{d}, J=8.0 \mathrm{~Hz}, \mathrm{H}_{7^{\prime}}\right), 7.84\left(3 \mathrm{H}, \mathrm{m}, \mathrm{H}_{2^{\prime}}, \mathrm{H}_{4^{\prime}}, \mathrm{NH}_{1}\right)$, $11.69\left(1 \mathrm{H}, \mathrm{d}, J=1.0 \mathrm{~Hz}, \mathrm{NH}_{\text {indole }}\right)$.

${ }^{13} \mathrm{C}$ NMR (100 MHz, DMSO- $\left.d_{6}\right): 48.3\left(\mathrm{CH}_{2}\right), 109.0,124.8$, 136.9, 152.7 (C quat), 112.1, 114.4, 119.9, 120.6, 122.1, 126.7 ( C tert $), 175.0(\mathrm{C}=\mathrm{O})$.

4.4.6. 3-(5-Methyl- $1 H$-indol-3-yl)- $1 H$-pyrrole (2b). Green solid. Mp $110^{\circ} \mathrm{C}$. IR (KBr) $\nu_{\mathrm{NH}} 3423 \mathrm{~cm}^{-1}$. HRMS (ESI+) $[\mathrm{M}+\mathrm{H}]^{+}$calcd for $\mathrm{C}_{13} \mathrm{H}_{13} \mathrm{~N}_{2}$ 197.1079, found 197.1084.

${ }^{1} \mathrm{H}$ NMR (400 MHz, DMSO- $\left.d_{6}\right): 2.44(3 \mathrm{H}, \mathrm{s}), 6.39$ (1H, pq, $J=2.0 \mathrm{~Hz}), 6.82(1 \mathrm{H}, \quad \mathrm{pq}, J=2.0 \mathrm{~Hz}), 6.94 \quad(1 \mathrm{H}, \quad \mathrm{dd}$, $\left.J_{1}=8.0 \mathrm{~Hz}, J_{2}=1.5 \mathrm{~Hz}\right), 7.11(1 \mathrm{H}, \mathrm{pq}, J=2.0 \mathrm{~Hz}), 7.28$ $(1 \mathrm{H}, \mathrm{d}, J=8.0 \mathrm{~Hz}), 7.37(1 \mathrm{H}, \mathrm{d}, J=2.5 \mathrm{~Hz}), 10.80(1 \mathrm{H}, \mathrm{s}$, $\mathrm{NH}), 10.74(1 \mathrm{H}, \mathrm{s}, \mathrm{NH})$.

${ }^{13} \mathrm{C}$ NMR $\left(100 \mathrm{MHz}\right.$, DMSO- $\left.d_{6}\right): 21.3\left(\mathrm{CH}_{3}\right), 106.1,111.0$, 113.3, 117.7, 119.1, 120.7, 122.3 (C tert), 111.1, 117.6, 125.7, 126.9, 134.9 (C quat).

4.4.7. 3-(5-Methyl-1H-indol-3-yl)-1H-5-hydroxy-2,5-dihydro-pyrrol-2-one (3b). Off-white solid. $\mathrm{Mp}>300{ }^{\circ} \mathrm{C}$. IR $(\mathrm{KBr}) \nu_{\mathrm{C}=\mathrm{C}} 1633 \mathrm{~cm}^{-1}, \nu_{\mathrm{C}=\mathrm{O}} 1697 \mathrm{~cm}^{-1}, \nu_{\mathrm{NH}, \mathrm{OH}}$ $3200-3500 \mathrm{~cm}^{-1}$. HRMS (ESI+) $\left[\mathrm{M}+\mathrm{H}-\mathrm{H}_{2} \mathrm{O}\right]^{+}$calcd for $\mathrm{C}_{13} \mathrm{H}_{11} \mathrm{~N}_{2} \mathrm{O} 211.0871$, found 211.0871 .

${ }^{1} \mathrm{H}$ NMR (400 MHz, DMSO- $\left.d_{6}\right): 2.48(3 \mathrm{H}, \mathrm{s}), 5.59(1 \mathrm{H}, \mathrm{d}$, $J=7.5 \mathrm{~Hz}), 5.99(1 \mathrm{H}, \mathrm{d}, J=8.5 \mathrm{~Hz}, \mathrm{OH}), 7.04(1 \mathrm{H}, \mathrm{t}$, $J=8.0 \mathrm{~Hz}), 7.14\left(1 \mathrm{H}, \mathrm{s}, \mathrm{H}_{4}\right), 7.38(1 \mathrm{H}, \mathrm{d}, J=8.0 \mathrm{~Hz}), 7.73$ $(1 \mathrm{H}, \mathrm{s}), 8.25(1 \mathrm{H}, \mathrm{d}, J=3.0 \mathrm{~Hz}), 8.65(1 \mathrm{H}, \mathrm{s}, \mathrm{NH}), 11.32$ $(1 \mathrm{H}, \mathrm{s}, \mathrm{NH})$

${ }^{13} \mathrm{C} \mathrm{NMR}\left(100 \mathrm{MHz}, \mathrm{DMSO}-d_{6}\right): 21.3\left(\mathrm{CH}_{3}\right), 78.3(\mathrm{CHOH})$, $105.6,125.8,128.7,130.8,134.5$ (C quat), 111.6, 119.5, $123.3,126.5,133.5(\mathrm{C}$ tert $), 171.8(\mathrm{C}=\mathrm{O})$.

4.4.8. 3-(5-Methyl-1H-indol-3-yl)- $1 H$-2,5-dihydro-pyrrol-2-one (4b). Ochre solid. $\mathrm{Mp}>300^{\circ} \mathrm{C}$. IR $(\mathrm{KBr}) \nu_{\mathrm{C}=\mathrm{C}}$ $1606 \mathrm{~cm}^{-1}, \quad \nu_{\mathrm{C}=\mathrm{O}} \quad 1649 \mathrm{~cm}^{-1}, \quad \nu_{\mathrm{NH}} \quad 3100-3300 \mathrm{~cm}^{-1}$. HRMS (ESI+) $[\mathrm{M}+\mathrm{Na}]^{+}$calcd for $\mathrm{C}_{13} \mathrm{H}_{12} \mathrm{~N}_{2} \mathrm{ONa}$ 235.0847 , found 235.0853 .

${ }^{1} \mathrm{H}$ NMR (400 MHz, DMSO- $\left.d_{6}\right): 2.47$ (3H, s), $4.05(2 \mathrm{H}, \mathrm{s})$, $7.02\left(1 \mathrm{H}, \quad \mathrm{dd}, \quad J_{1}=8.0 \mathrm{~Hz}, J_{2}=1.0 \mathrm{~Hz}\right), 7.36(1 \mathrm{H}, \mathrm{d}$, $J=8.0 \mathrm{~Hz}), 7.41\left(1 \mathrm{H}, \mathrm{d}, J=1.5 \mathrm{~Hz}, \mathrm{H}_{4}\right), 7.71(1 \mathrm{H}$, br s), $8.22(1 \mathrm{H}, \mathrm{d}, J=2.5 \mathrm{~Hz}), 8.40(1 \mathrm{H}, \mathrm{s}, \mathrm{NH}), 11.21(1 \mathrm{H}, \mathrm{s}, \mathrm{NH})$.

${ }^{13} \mathrm{C}$ NMR (100 MHz, DMSO- $\left.d_{6}\right): 21.3\left(\mathrm{CH}_{3}\right), 45.9\left(\mathrm{CH}_{2} \mathrm{~N}\right)$, 106.3, 125.7, 128.3, 130.8, 134.4 (C quat), 111.5, 119.3, $123.1,125.5,131.5(\mathrm{C}$ tert $), 173.2(\mathrm{C}=\mathrm{O})$. 
4.4.9. 4-(5-Methyl-1H-indol-3-yl)-1H-5-hydroxy-2,5-dihydro-pyrrol-2-one (5b). Off-white solid. Mp $104{ }^{\circ} \mathrm{C}$. IR $(\mathrm{KBr}) \nu_{\mathrm{C}=\mathrm{C}} 1615 \mathrm{~cm}^{-1}, \quad \nu_{\mathrm{C}=\mathrm{O}} 1682 \mathrm{~cm}^{-1}, \quad \nu_{\mathrm{NH}} 3274$, $3398 \mathrm{~cm}^{-1}$. HRMS (ESI+) $[\mathrm{M}+\mathrm{Na}]^{+}$calcd for $\mathrm{C}_{13} \mathrm{H}_{12} \mathrm{~N}_{2} \mathrm{O}_{2} \mathrm{Na} 251.0796$, found 251.0805.

${ }^{1} \mathrm{H}$ NMR (400 MHz, DMSO- $\left.d_{6}\right): 2.47$ (3H, s), 5.83 (1H, dd, $\left.J_{1}=9.5 \mathrm{~Hz}, J_{2}=1.5 \mathrm{~Hz}\right), 6.21\left(1 \mathrm{H}, \mathrm{d}, J=1.0 \mathrm{~Hz}, \mathrm{H}_{3}\right), 6.23$ $(1 \mathrm{H}, \mathrm{d}, J=9.5 \mathrm{~Hz}), 7.05\left(1 \mathrm{H}, \mathrm{dd}, J_{1}=8.0 \mathrm{~Hz}, J_{2}=1.0 \mathrm{~Hz}\right)$, $7.39(1 \mathrm{H}, \mathrm{d}, J=8.0 \mathrm{~Hz}), 7.70(1 \mathrm{H}$, br s), $7.82(1 \mathrm{H}, \mathrm{d}$, $J=2.5 \mathrm{~Hz}), 8.16(1 \mathrm{H}, \mathrm{s}, \mathrm{NH}), 11.59(1 \mathrm{H}, \mathrm{s}, \mathrm{NH})$.

${ }^{13} \mathrm{C}$ NMR (100 MHz, DMSO- $\left.d_{6}\right): 21.2\left(\mathrm{CH}_{3}\right), 80.5(\mathrm{CHOH})$, 107.6, 125.6, 129.4, 134.9, 154.5 (C quat), 111.7, 113.0, 119.8, 123.6, 128.4 (C tert), $172.9(\mathrm{C}=\mathrm{O})$.

4.4.10. 4-(5-Methyl-1H-indol-3-yl)-1H-2,5-dihydro-pyrrol-2-one (6b). Off-white solid. Mp $140^{\circ} \mathrm{C}$. IR $(\mathrm{KBr})$ $\nu_{\mathrm{C}=\mathrm{C}} 1605 \mathrm{~cm}^{-1}, \nu_{\mathrm{C}=\mathrm{O}} 1649 \mathrm{~cm}^{-1}, \nu_{\mathrm{NH}} 3035-3430 \mathrm{~cm}^{-1}$. HRMS (ESI+) $[\mathrm{M}+\mathrm{H}]^{+}$calcd for $\mathrm{C}_{13} \mathrm{H}_{13} \mathrm{~N}_{2} \mathrm{O} 213.1028$, found 213.1027 .

${ }^{1} \mathrm{H}$ NMR (400 MHz, DMSO- $\left.d_{6}\right): 2.46(3 \mathrm{H}, \mathrm{s}), 4.43(2 \mathrm{H}, \mathrm{s})$, $6.28\left(1 \mathrm{H}, \mathrm{d}, J=1.0 \mathrm{~Hz}, \mathrm{H}_{3}\right), 7.05\left(1 \mathrm{H}, \mathrm{dd}, J_{1}=8.0 \mathrm{~Hz}\right.$, $\left.J_{2}=1.0 \mathrm{~Hz}\right), 7.37(1 \mathrm{H}, \mathrm{d}, J=8.0 \mathrm{~Hz}), 7.69(1 \mathrm{H}, \mathrm{s}), 7.81$ $(1 \mathrm{H}, \mathrm{s}), 7.82(1 \mathrm{H}, \mathrm{s}), 11.58(1 \mathrm{H}, \mathrm{s}, \mathrm{NH})$.

${ }^{13} \mathrm{C}$ NMR (100 MHz, DMSO- $\left.d_{6}\right): 21.2\left(\mathrm{CH}_{3}\right), 48.3\left(\mathrm{CH}_{2} \mathrm{~N}\right)$, 108.6, 125.1, 129.4, 135.1, 152.8 (C quat), 111.8, 114.1, 119.6, 123.6, 126.7 (C tert), $175.1(\mathrm{C}=\mathrm{O})$.

4.4.11.3-(5-Benzyloxy- $1 H$-indol-3-yl)- $1 H$-5-hydroxy-2,5dihydro-pyrrol-2-one (3c). Off-white solid. $\mathrm{Mp}>200^{\circ} \mathrm{C}$ (decomposition). IR $(\mathrm{KBr}) \quad \nu_{\mathrm{C}=\mathrm{C}} 1631 \mathrm{~cm}^{-1}, \quad \nu_{\mathrm{C}=\mathrm{O}}$ $1706 \mathrm{~cm}^{-1}, \quad \nu_{\mathrm{NH}, \mathrm{OH}} \quad 3100-3500 \mathrm{~cm}^{-1}$. HRMS (ESI+) $[\mathrm{M}+\mathrm{H}]^{+}$calcd for $\mathrm{C}_{19} \mathrm{H}_{17} \mathrm{~N}_{2} \mathrm{O}_{3} 321.1239$, found 321.1256 .

${ }^{1} \mathrm{H}$ NMR (400 MHz, DMSO- $\left.d_{6}\right): 5.22\left(2 \mathrm{H}, \mathrm{s}, \mathrm{CH}_{2}\right), 5.58$ $\left(1 \mathrm{H}, \quad \mathrm{dt}, \quad J_{1}=9.0 \mathrm{~Hz}, \quad J_{2}=2.0 \mathrm{~Hz}, \mathrm{H}_{5}\right), 5.98(1 \mathrm{H}, \quad \mathrm{d}$, $J=9.0 \mathrm{~Hz}, \mathrm{OH}), 6.94\left(1 \mathrm{H}, \mathrm{dd}, J_{1}=9.0 \mathrm{~Hz}, J_{2}=2.0 \mathrm{~Hz}\right)$, $7.12(1 \mathrm{H}, \mathrm{t}, J=1.5 \mathrm{~Hz}), 7.36-7.46(5 \mathrm{H}, \mathrm{m}), 7.55(2 \mathrm{H}, \mathrm{d}$, $J=7.0 \mathrm{~Hz}), 8.25(1 \mathrm{H}, \mathrm{d}, J=3.0 \mathrm{~Hz}), 8.63(1 \mathrm{H}, \mathrm{s}, \mathrm{NH})$, $11.33(1 \mathrm{H}, \mathrm{d}, J=2.5 \mathrm{~Hz}, \mathrm{NH})$.

${ }^{13} \mathrm{C}$ NMR (100 MHz, DMSO- $\left.d_{6}\right): 69.9\left(\mathrm{CH}_{2} \mathrm{O}\right), 78.3$ $(\mathrm{CHOH}), 103.4,112.3,112.6,127.1,127.6$ (3C), 128.3 (2C), 133.5 (C tert), 105.9, 125.9, 130.6, 131.3, 137.8, 153.2 (C quat), $171.8(\mathrm{C}=\mathrm{O})$.

4.4.12. 3-(5-Benzyloxy- $1 H$-indol-3-yl)- $1 H$-2,5-dihydropyrrol-2-one (4c). Brown solid. Mp $185^{\circ} \mathrm{C}$. IR (KBr) $\nu_{\mathrm{C}=\mathrm{C}} 1620 \mathrm{~cm}^{-1}, \nu_{\mathrm{C}=\mathrm{O}} 1680 \mathrm{~cm}^{-1}, \nu_{\mathrm{NH}} 3100-3500 \mathrm{~cm}^{-1}$. Mass $(\mathrm{ESI}+)[\mathrm{M}+\mathrm{K}]^{+} 343,[\mathrm{M}+\mathrm{Na}]^{+} 327$.

${ }^{1} \mathrm{H}$ NMR (400 MHz, DMSO- $\left.d_{6}\right): 4.05(2 \mathrm{H}, \mathrm{s}), 5.20(2 \mathrm{H}, \mathrm{s})$, $6.92\left(1 \mathrm{H}, \mathrm{dd}, J_{1}=9.0 \mathrm{~Hz}, J_{2}=2.0 \mathrm{~Hz}\right), 7.33-7.47(6 \mathrm{H}, \mathrm{m})$, $7.54(2 \mathrm{H}, \mathrm{d}, J=7.5 \mathrm{~Hz}), 8.23(1 \mathrm{H}, \mathrm{d}, J=2.5 \mathrm{~Hz}), 8.41(1 \mathrm{H}$, $\mathrm{s}, \mathrm{NH}), 11.22(1 \mathrm{H}, \mathrm{s}, \mathrm{NH})$.

${ }^{13} \mathrm{C}$ NMR (100 MHz, DMSO- $\left.d_{6}\right): 46.0\left(\mathrm{CH}_{2} \mathrm{~N}\right), 69.9$ $\left(\mathrm{CH}_{2} \mathrm{OBn}\right), 103.4,112.0,112.4,126.1,127.6,127.7$ (2C), 128.3 (3C), 131.3 (C tert), 106.7, 125.8, 130.6, 131.2, $137.8,153.0$ (C quat), $173.1(\mathrm{C}=\mathrm{O})$.
4.4.13. 4-(5-Benzyloxy-1H-indol-3-yl)-1H-5-hydroxy-2,5dihydro-pyrrol-2-one (5c). Off-white solid. Mp 215$216^{\circ} \mathrm{C}$. IR (KBr) $\nu_{\mathrm{C}=\mathrm{C}} 1613 \mathrm{~cm}^{-1}, \nu_{\mathrm{C}=\mathrm{O}} 1681 \mathrm{~cm}^{-1}$, $\nu_{\mathrm{NH}, \mathrm{OH}} 3040-3663 \mathrm{~cm}^{-1}$. HRMS (ESI+) $[\mathrm{M}+\mathrm{H}]^{+}$calcd for $\mathrm{C}_{19} \mathrm{H}_{17} \mathrm{~N}_{2} \mathrm{O}_{3} 321.1239$, found 321.1242 .

${ }^{1} \mathrm{H}$ NMR (400 MHz, DMSO- $\left.d_{6}\right): 5.23(2 \mathrm{H}, \mathrm{s}), 5.81(1 \mathrm{H}, \mathrm{d}$, $J=9.5 \mathrm{~Hz}), 6.22(1 \mathrm{H}, \mathrm{s}), 6.23(1 \mathrm{H}, \mathrm{d}, J=9.0 \mathrm{~Hz}), 6.95(1 \mathrm{H}$, $\mathrm{d}, J=9.0 \mathrm{~Hz}), 7.34-7.46(5 \mathrm{H}, \mathrm{m}), 7.54(2 \mathrm{H}, \mathrm{d}, J=7.5 \mathrm{~Hz})$, $7.83(1 \mathrm{H}, \mathrm{s}), 8.17(1 \mathrm{H}, \mathrm{s}), 11.61(1 \mathrm{H}, \mathrm{s}, \mathrm{NH})$.

${ }^{13} \mathrm{C}$ NMR (100 MHz, DMSO- $\left.d_{6}\right): 69.7\left(\mathrm{CH}_{2} \mathrm{OBn}\right), 80.5$ $(\mathrm{CHOH}), 103.5,111.4,111.9,112.8,127.6(3 \mathrm{C}), 128.3$ (2C), 129.0 (C tert), 107.9, 125.8, 131.7, 137.7, 153.6, 154.3 (C quat), $173.0(\mathrm{C}=\mathrm{O})$.

4.4.14. 4-(5-Benzyloxy- $1 H$-indol-3-yl)- $1 H$-2,5-dihydropyrrol-2-one (6c). Off-white solid. Mp $235-237^{\circ} \mathrm{C}$. IR $(\mathrm{KBr}) \nu_{\mathrm{C}=\mathrm{C}} 1606 \mathrm{~cm}^{-1}, \quad \nu_{\mathrm{C}=\mathrm{O}} 1651 \mathrm{~cm}^{-1}, \nu_{\mathrm{NH}} 3200-$ $3430 \mathrm{~cm}^{-1}$. HRMS (ESI+) $[\mathrm{M}+\mathrm{H}]^{+}$calcd for $\mathrm{C}_{19} \mathrm{H}_{17} \mathrm{~N}_{2} \mathrm{O}_{2}$ 305.1290 , found 305.1297 .

${ }^{1} \mathrm{H}$ NMR (400 MHz, DMSO- $\left.d_{6}\right): 4.41(2 \mathrm{H}, \mathrm{s}), 5.23(2 \mathrm{H}, \mathrm{s})$, $6.29\left(1 \mathrm{H}, \mathrm{s}, \mathrm{H}_{3}\right), 6.94(1 \mathrm{H}, \mathrm{d}, J=9.0 \mathrm{~Hz}), 7.34-7.46(5 \mathrm{H}, \mathrm{m})$, $7.54(2 \mathrm{H}, \mathrm{d}, J=7.5 \mathrm{~Hz}), 7.82(2 \mathrm{H}, \mathrm{s}), 11.59(1 \mathrm{H}, \mathrm{s}, \mathrm{NH})$.

${ }^{13} \mathrm{C}$ NMR (100 MHz, DMSO- $\left.d_{6}\right): 48.3,69.7\left(\mathrm{CH}_{2}\right), 103.2$, $103.5,112.9,104.0,114.0,127.2,127.6(2 \mathrm{C}), 128.3(2 \mathrm{C})$, 129.0 (C tert), 108.9, 125.3, 132.0, 137.7, 152.7, 153.6 (C quat), $175.2(\mathrm{CO})$.

4.4.15. 4-(5-Hydroxy- $1 H$-indol-3-yl)- $1 H$-5-hydroxy-2,5dihydro-pyrrol-2-one (5d). Brown solid. Mp 102-104 ${ }^{\circ} \mathrm{C}$. IR $(\mathrm{KBr}) \nu_{\mathrm{C}=\mathrm{C}} 1614 \mathrm{~cm}^{-1}, \nu_{\mathrm{C}=\mathrm{O}} 1678 \mathrm{~cm}^{-1}, \nu_{\mathrm{NH}, \mathrm{OH}}$ 2981-3599 $\mathrm{cm}^{-1}$. HRMS (ESI+) $[\mathrm{M}+\mathrm{Na}]^{+}$calcd for $\mathrm{C}_{12} \mathrm{H}_{10} \mathrm{~N}_{2} \mathrm{O}_{3} \mathrm{Na} 253.0589$, found 253.0595.

${ }^{1} \mathrm{H}$ NMR (400 MHz, DMSO- $\left.d_{6}\right): 5.81(1 \mathrm{H}, \mathrm{d}, J=10.0 \mathrm{~Hz})$, $5.93(1 \mathrm{H}, \mathrm{s}), 6.23(1 \mathrm{H}, \mathrm{d}, J=10.0 \mathrm{~Hz}, \mathrm{OH}), 6.75(1 \mathrm{H}, \mathrm{d}$, $J=9.0 \mathrm{~Hz}), 7.14(1 \mathrm{H}, \mathrm{s}), 7.31 \quad\left(1 \mathrm{H}, \quad \mathrm{dd}, J_{1}=9.0 \mathrm{~Hz}\right.$, $\left.J_{2}=1.0 \mathrm{~Hz}\right), 7.78(1 \mathrm{H}, \mathrm{s}), 8.16(1 \mathrm{H}, \mathrm{s}), 8.97(1 \mathrm{H}, \mathrm{s}), 11.49$ ( $\left.1 \mathrm{H}, \mathrm{s}, \mathrm{NH}_{\text {indole }}\right)$.

${ }^{13} \mathrm{C}$ NMR (100 MHz, DMSO- $\left.d_{6}\right): 80.5(\mathrm{CHOH}), 104.2$, $111.9,112.0,112.6,128.8$ (C tert), 107.2, 126.3, 130.9, 152.1, 154.9 (C quat), $172.8(\mathrm{C}=\mathrm{O})$.

4.4.16. 3-(5-Hydroxy- $1 H$-indol-3-yl)- $1 H$-2,5-dihydropyrrol-2-one (4d). Brown solid. Mp $180^{\circ} \mathrm{C}$. IR (KBr) $\nu_{\mathrm{C}=\mathrm{C}} 1618 \mathrm{~cm}^{-1}, \nu_{\mathrm{C}=\mathrm{O}} 1672 \mathrm{~cm}^{-1}, \nu_{\mathrm{NH}} 3100-3550 \mathrm{~cm}^{-1}$. Mass $(\mathrm{APCI}+)[\mathrm{M}+\mathrm{H}]^{+} 215$.

${ }^{1} \mathrm{H}$ NMR (400 MHz, DMSO- $\left.d_{6}\right): 4.04(2 \mathrm{H}, \mathrm{s}), 6.72(1 \mathrm{H}, \mathrm{d}$, $J=9.0 \mathrm{~Hz}), 7.20(1 \mathrm{H}, \mathrm{s}), 7.21(1 \mathrm{H}, \mathrm{s}), 7.27(1 \mathrm{H}, \mathrm{d}$, $J=9.0 \mathrm{~Hz}), 8.18(1 \mathrm{H}, \mathrm{s}), 8.39(1 \mathrm{H}, \mathrm{s}), 8.84(1 \mathrm{H}$, br s$)$, $11.08(1 \mathrm{H}, \mathrm{s}, \mathrm{NH})$.

${ }^{13} \mathrm{C}$ NMR (100 MHz, DMSO- $\left.d_{6}\right): 45.9\left(\mathrm{CH}_{2}\right), 103.9,111.6$, 112.1, 125.8, 130.5 (C tert), 106.0, 126.3, 130.4, 131.0, 151.4 (C quat), $173.2(\mathrm{C}=\mathrm{O})$.

4.4.17. $2 H, 5 H, 7 H-1,3,4,6$-Tetrahydro-dipyrrolo[3,4$a: 3,4-c]$ carbazole-1,4,6-trione (7). A mixture of maleimide 
(244 mg, $2.51 \mathrm{mmol})$ and compound 4a (100 mg, $0.505 \mathrm{mmol})$ in xylene $(14 \mathrm{~mL})$ was refluxed for 3 days. After cooling, the yellow precipitate was filtered off washed with xylene and dried. The yellow solid (144 mg, $0.491 \mathrm{mmol}, 97 \%$ yield) corresponds to an isomeric mixture of Diels-Alder adducts. The mixture of isomers $(84 \mathrm{mg}$, $0.286 \mathrm{mmol})$ in dioxane $(22 \mathrm{~mL})$ was refluxed for $36 \mathrm{~h}$ in the presence of trifluoroacetic acid $(293 \mu \mathrm{L})$. After evaporation, EtOAc was added to the residue. The mixture was filtered off. The solid was successively washed with saturated aqueous $\mathrm{NaHCO}_{3}$, brine, and EtOAc to give compound 7 as a yellow-brown solid ( $22 \mathrm{mg}, 0.075 \mathrm{mmol}, 27 \%$ yield).

$\mathrm{Mp}>310^{\circ} \mathrm{C}$. IR $(\mathrm{KBr}) \nu_{\mathrm{C}=\mathrm{O}} 1690,1700,1720 \mathrm{~cm}^{-1}, \nu_{\mathrm{NH}}$ $3387 \mathrm{~cm}^{-1}$. HRMS (ESI+) $[\mathrm{M}+\mathrm{H}]^{+}$calcd for $\mathrm{C}_{16} \mathrm{H}_{10} \mathrm{~N}_{3} \mathrm{O}_{3}$ 292.0722 , found 292.0745 .

${ }^{1} \mathrm{H}$ NMR (400 MHz, DMSO- $\left.d_{6}\right): 4.77(2 \mathrm{H}, \mathrm{s}), 7.34(1 \mathrm{H}, \mathrm{t}$, $J=7.5 \mathrm{~Hz}), \quad 7.61 \quad(1 \mathrm{H}, \quad \mathrm{t}, \quad J=8.0 \mathrm{~Hz}), \quad 7.73 \quad(1 \mathrm{H}, \quad \mathrm{d}$, $J=7.5 \mathrm{~Hz}), 9.08(1 \mathrm{H}, \mathrm{s}), 9.25(1 \mathrm{H}, \mathrm{d}, J=8.0 \mathrm{~Hz}), 11.40$ $(1 \mathrm{H}, \mathrm{s}), 12.37(1 \mathrm{H}, \mathrm{s})$.

Due to its insolubility, the ${ }^{13} \mathrm{C}$ NMR spectrum could not be recorded.

4.4.18. 10-Methyl-2H,5H,7H-1,3,3a,3b,4,6,6a,11c-octahydro-dipyrrolo[3,4-a:3,4-c]carbazole-1,4,6-trione (8). A mixture of maleimide $(179 \mathrm{mg}, 1.84 \mathrm{mmol})$ and compound $4 \mathrm{~b}(78 \mathrm{mg}, 0.37 \mathrm{mmol})$ in xylene $(10 \mathrm{~mL})$ was refluxed for 3 days. After cooling, the mixture was filtered off and the solid residue was washed with xylene then dried to give $\mathbf{8}$ as an off-white solid (116 mg, $0.37 \mathrm{mmol}, 100 \%$ yield).

$\mathrm{Mp}>295^{\circ} \mathrm{C}$. IR $(\mathrm{KBr}) \nu_{\mathrm{C}=\mathrm{O}} 1715,1777 \mathrm{~cm}^{-1}, \nu_{\mathrm{NH}} 3061-$ $3684 \mathrm{~cm}^{-1}$. HRMS (ESI+) $[\mathrm{M}+\mathrm{H}]^{+}$calcd for $\mathrm{C}_{17} \mathrm{H}_{16} \mathrm{~N}_{3} \mathrm{O}_{3}$ 310.1192 , found 310.1178 .

${ }^{1} \mathrm{H}$ NMR (400 MHz, DMSO- $\left.d_{6}\right): 2.37(3 \mathrm{H}, \mathrm{s}), 2.82(1 \mathrm{H}, \mathrm{t}$, $J=9.5 \mathrm{~Hz}), 3.11(1 \mathrm{H}, \mathrm{t}, J=9.0 \mathrm{~Hz}), 3.25(1 \mathrm{H}, \mathrm{m}), 3.51$ $(1 \mathrm{H}, \mathrm{t}, J=7.0 \mathrm{~Hz}), 3.56(1 \mathrm{H}, \mathrm{d}, J=7.0 \mathrm{~Hz}), 4.38(1 \mathrm{H}, \mathrm{d}$, $J=8.5 \mathrm{~Hz}), \quad 6.92(1 \mathrm{H}, \quad \mathrm{d}, \quad J=8.0 \mathrm{~Hz}), 7.28 \quad(1 \mathrm{H}, \mathrm{d}$, $J=8.5 \mathrm{~Hz}), 7.58(1 \mathrm{H}, \mathrm{s}, \mathrm{NH}), 7.75(1 \mathrm{H}, \mathrm{s}), 11.12(1 \mathrm{H}, \mathrm{s}$, $\mathrm{NH}), 11.52(1 \mathrm{H}, \mathrm{s}, \mathrm{NH})$.

${ }^{13} \mathrm{C}$ NMR (100 MHz, DMSO- $\left.d_{6}\right): 21.3\left(\mathrm{CH}_{3}\right), 41.3\left(\mathrm{CH}_{2} \mathrm{~N}\right)$, 35.6, 38.6, 40.3, $40.7(\mathrm{CH}), 110.7,120.2,122.8$ (C tert), $102.2,125.9,126.3,126.7,135.3$ (C quat), 175.1, 177.0, $178.5(\mathrm{C}=\mathrm{O})$.

4.4.19. 10-Methyl-2H,5H,7H-1,3,4,6-tetrahydro-dipyrrolo[3,4-a:3,4-c] carbazole-1,4,6-trione (9). A solution of $\mathbf{8}(104 \mathrm{mg}, 0.34 \mathrm{mmol})$ in dioxane $(11 \mathrm{~mL})$ and trifluoroacetic acid $(266 \mu \mathrm{L})$ was stirred at $80^{\circ} \mathrm{C}$ for $48 \mathrm{~h}$. After evaporation, water was added to the residue, the mixture was filtered off, the solid was washed with water and with small amounts of EtOAc to give 9 as an orange solid ( $80 \mathrm{mg}$, $0.263 \mathrm{mmol}, 78 \%$ yield).

$\mathrm{Mp}>300^{\circ} \mathrm{C}$. IR $(\mathrm{KBr}) \nu_{\mathrm{C}=\mathrm{O}} 1716,1758 \mathrm{~cm}^{-1}, \nu_{\mathrm{NH}} 3208-$ $3664 \mathrm{~cm}^{-1}$. HRMS (ESI+) $[\mathrm{M}+\mathrm{H}]^{+}$calcd for $\mathrm{C}_{17} \mathrm{H}_{12} \mathrm{~N}_{3} \mathrm{O}_{3}$ 306.0879 , found 306.0894 .
${ }^{1} \mathrm{H}$ NMR (400 MHz, DMSO- $\left.d_{6}\right): 2.50(3 \mathrm{H}, \mathrm{s}), 4.75(2 \mathrm{H}, \mathrm{s})$, $7.43(1 \mathrm{H}, \mathrm{d}, J=8.0 \mathrm{~Hz}), 7.61(1 \mathrm{H}, \mathrm{d}, J=8.0 \mathrm{~Hz}), 9.05(2 \mathrm{H}, \mathrm{s})$, $11.36(1 \mathrm{H}, \mathrm{s}), 12.23(1 \mathrm{H}, \mathrm{s})$.

Due to its insolubility, the ${ }^{13} \mathrm{C}$ NMR spectrum could not be recorded.

4.4.20. 10-Benzyloxy-2H,5H,7H-1,3,4,6-tetrahydro-dipyrrolo[3,4-a:3,4-c]carbazole-1,4,6-trione (10). A mixture of maleimide (122 mg, $1.25 \mathrm{mmol})$ and compound $4 \mathrm{c}$ (74 mg, $0.25 \mathrm{mmol})$ in xylene $(6 \mathrm{~mL})$ was refluxed for $18 \mathrm{~h}$. After cooling, the mixture was filtered off and the solid residue was washed with $\mathrm{CH}_{2} \mathrm{Cl}_{2}$ then was dried to give an orange solid as a mixture of isomers $(97 \mathrm{mg}, 0.25 \mathrm{mmol}$, quantitative yield).

The mixture of isomers $(90 \mathrm{mg}, 0.23 \mathrm{mmol})$, dioxane $(6 \mathrm{~mL})$ and trifluoroacetic acid $(2.2 \mathrm{mmol}, 172 \mu \mathrm{L})$ was stirred at $80^{\circ} \mathrm{C}$ for $48 \mathrm{~h}$. After evaporation, water was added to the residue, the mixture was filtered off and the solid residue was washed repeatedly with water and small amounts of EtOAc to give 10 (61 mg, $0.15 \mathrm{mmol}, 65 \%$ yield $)$ as a dark red solid.

$\mathrm{Mp}>300^{\circ} \mathrm{C}$. IR $(\mathrm{KBr}) \nu_{\mathrm{C}=\mathrm{C}} 1617 \mathrm{~cm}^{-1}, \nu_{\mathrm{C}=\mathrm{O}} 1722$, $1774 \mathrm{~cm}^{-1}, \nu_{\mathrm{NH}} 3100-3550 \mathrm{~cm}^{-1}$. HRMS (ESI+) $[\mathrm{M}+\mathrm{Na}]^{+}$ calcd for $\mathrm{C}_{23} \mathrm{H}_{15} \mathrm{~N}_{3} \mathrm{O}_{4} \mathrm{Na} 420.0960$, found 420.0974 .

${ }^{1} \mathrm{H}$ NMR (400 MHz, DMSO- $\left.d_{6}\right): 4.76(2 \mathrm{H}, \mathrm{s}), 5.21(2 \mathrm{H}, \mathrm{s})$, $7.33-7.65(7 \mathrm{H}, \mathrm{m}), 8.95(1 \mathrm{H}, \mathrm{d}, J=2.0 \mathrm{~Hz}), 9.07(1 \mathrm{H}, \mathrm{s})$, $11.37(1 \mathrm{H}, \mathrm{s}), 12.21(1 \mathrm{H}, \mathrm{s})$.

Due to its insolubility, the ${ }^{13} \mathrm{C}$ NMR spectrum could not be recorded.

4.4.21. 10-Hydroxy-2H,5H,7H-1,3,3a,3b,4,6,6a,11c-octahydro-dipyrrolo[3,4-a:3,4-c]carbazole-1,4,6-trione (11). A mixture of maleimide $(40 \mathrm{mg}, 0.48 \mathrm{mmol})$ and $4 d$ (92 $\mathrm{mg}, 0.43 \mathrm{mmol})$ in xylene $(5 \mathrm{~mL})$ was refluxed for $24 \mathrm{~h}$. After cooling, the mixture was filtered off and the solid residue was washed with $\mathrm{CH}_{2} \mathrm{Cl}_{2}$ then was dried to give $\mathbf{1 1}$ (40 mg, $0.13 \mathrm{mmol}, 30 \%$ yield) as a dark orange solid.

$\mathrm{Mp}>300{ }^{\circ} \mathrm{C}$. IR $(\mathrm{KBr}) \nu_{\mathrm{C}=\mathrm{O}} 1691,1763 \mathrm{~cm}^{-1}, \nu_{\mathrm{NH}, \mathrm{OH}}$ $3300-3550 \mathrm{~cm}^{-1}$. Mass (ESI+) $[\mathrm{M}+\mathrm{H}]^{+} 312$.

${ }^{1} \mathrm{H}$ NMR (400 MHz, DMSO- $\left.d_{6}\right): 2.94(1 \mathrm{H}, \mathrm{m}), 3.27(1 \mathrm{H}, \mathrm{t}$, $J=8.0 \mathrm{~Hz}), 3.47(1 \mathrm{H}, \mathrm{t}, J=9.0 \mathrm{~Hz}), 3.61(1 \mathrm{H}, \mathrm{t}, J=10.0 \mathrm{~Hz})$, $4.23-4.29(2 \mathrm{H}, \mathrm{m}), 6.28(1 \mathrm{H}, \mathrm{s}), 6.59(1 \mathrm{H}, \mathrm{d}, J=8.0 \mathrm{~Hz})$, $6.63(1 \mathrm{H}, \mathrm{d}, J=8.0 \mathrm{~Hz}), 7.83(1 \mathrm{H}, \mathrm{s}), 8.06(1 \mathrm{H}, \mathrm{s}), 8.67$ $(1 \mathrm{H}, \mathrm{s}), 10.94(1 \mathrm{H}, \mathrm{s})$.

${ }^{13} \mathrm{C}$ NMR (100 MHz, DMSO- $\left.d_{6}\right): 41.1\left(\mathrm{CH}_{2} \mathrm{~N}\right), 36.2,42.7$, $60.5,70.0(\mathrm{CH}), 110.4,113.2,119.8(\mathrm{C}$ tert arom $), 119.5$, $122.8,143.1,148.8,149.8$ (C quat arom), 168.4, 175.7, $178.4(\mathrm{C}=\mathrm{O})$.

4.4.22. 10-Hydroxy-2H,5H,7H-1,3,4,6-tetrahydro-dipyrrolo[3,4- $a: 3,4-c]$ carbazole-1,4,6-trione (12). A solution of $11(80 \mathrm{mg}, 0.257 \mathrm{mmol})$ in dioxane $(8 \mathrm{~mL})$ was stirred at $80^{\circ} \mathrm{C}$ for $48 \mathrm{~h}$ in the presence of trifluoroacetic acid $(2.56 \mathrm{mmol}, 200 \mu \mathrm{L})$. After evaporation, water was added to the residue, the mixture was filtered off and the solid residue was washed successively with water and small amounts 
of EtOAc to give 12 (52 mg, $0.169 \mathrm{mmol}, 66 \%$ yield) as a red solid.

$\mathrm{Mp}>300^{\circ} \mathrm{C}$. IR $(\mathrm{KBr}) \nu_{\mathrm{C}=\mathrm{O}} 1711 \mathrm{~cm}^{-1}, \nu_{\mathrm{NH}, \mathrm{OH}} 3200-$ $3672 \mathrm{~cm}^{-1}$. HRMS (ESI+) $[\mathrm{M}+\mathrm{H}]^{+}$calcd for $\mathrm{C}_{16} \mathrm{H}_{10} \mathrm{~N}_{3} \mathrm{O}_{4}$ 308.0671 , found 308.0672 .

${ }^{1} \mathrm{H}$ NMR (400 MHz, DMSO- $\left.d_{6}\right): 4.75(2 \mathrm{H}, \mathrm{s}), 7.11(1 \mathrm{H}, \mathrm{dd}$, $\left.J_{1}=9.0 \mathrm{~Hz}, J_{2}=2.0 \mathrm{~Hz}\right), 7.54(1 \mathrm{H}, \mathrm{d}, J=9.0 \mathrm{~Hz}), 8.66(1 \mathrm{H}, \mathrm{d}$, $J=2.0 \mathrm{~Hz}), 9.02(1 \mathrm{H}, \mathrm{s}), 9.27(1 \mathrm{H}, \mathrm{s}), 11.33(1 \mathrm{H}, \mathrm{s}), 12.06$ $(1 \mathrm{H}, \mathrm{s})$.

Due to its insolubility, the ${ }^{13} \mathrm{C}$ NMR spectrum could not be recorded.

4.4.23. $2 H, 5 H, 7 H-1,3,4,6$-Tetrahydro-dipyrrolo[3,4- $a$ : 3,4-c carbazole-3,4,6-trione (13). A mixture of 5a (241 mg, $1.126 \mathrm{mmol}$ ) and maleimide (131 mg, $1.35 \mathrm{mmol})$ in xylene $(20 \mathrm{~mL})$ was refluxed for 4 days. After filtration, the solid residue was washed with water to give an isomeric mixture of the Diels-Alder adducts as a brown solid (254 mg, $0.86 \mathrm{mmol}, 77 \%$ yield).

A solution of the isomeric mixture $(60 \mathrm{mg}, 0.205 \mathrm{mmol})$ in dioxane $(7 \mathrm{~mL})$ was refluxed for 21 days in the presence of trifluoroacetic acid $(900 \mu \mathrm{L})$. After evaporation, EtOAc was added to the residue. The mixture was filtered off, and the solid was successively washed with saturated aqueous $\mathrm{NaHCO}_{3}$, water, and EtOAc to give $\mathbf{1 3}$ as a brown solid (32 mg, $0.110 \mathrm{mmol}, 54 \%$ yield).

$\mathrm{Mp}>300^{\circ} \mathrm{C}$. IR $(\mathrm{KBr}) \nu_{\mathrm{C}=\mathrm{O}} 1710,1720,1780 \mathrm{~cm}^{-1}, \nu_{\mathrm{N}-\mathrm{H}}$ $3000-3500 \mathrm{~cm}^{-1}$. Mass (ESI+) $[\mathrm{M}+\mathrm{H}]^{+}$292. HRMS (ESI+) $[\mathrm{M}+\mathrm{Na}]^{+}$calcd for $\mathrm{C}_{16} \mathrm{H}_{9} \mathrm{~N}_{3} \mathrm{O}_{3} \mathrm{Na} 314.0542$, found 314.0556 .

${ }^{1} \mathrm{H}$ NMR (400 MHz, DMSO): $5.03(2 \mathrm{H}, \mathrm{s}), 7.41(1 \mathrm{H}, \mathrm{t}$, $J=7.5 \mathrm{~Hz}), 7.63(1 \mathrm{H}, \mathrm{t}, J=7.5 \mathrm{~Hz}), 7.78(1 \mathrm{H}, \mathrm{d}, J=8.0 \mathrm{~Hz})$, $8.12(1 \mathrm{H}, \mathrm{d}, J=8.0 \mathrm{~Hz}), 8.76(1 \mathrm{H}, \mathrm{s}, \mathrm{NH}), 11.21(1 \mathrm{H}, \mathrm{s}, \mathrm{NH})$, $12.46(1 \mathrm{H}, \mathrm{s}, \mathrm{NH})$. Due to its insolubility, the ${ }^{13} \mathrm{C}$ NMR spectrum could not be recorded.

4.4.24. 10-Methyl-2H,5H,7H-1,3,4,6-tetrahydro-dipyrrolo[3,4-a:3,4-c] carbazole-3,4,6-trione (14). A mixture of compound 5b $(120 \mathrm{mg}, 0.53 \mathrm{mmol})$ and maleimide $(61 \mathrm{mg}, 0.62 \mathrm{mmol})$ in xylene $(5 \mathrm{~mL})$ was refluxed for 3 days. After filtration, the solid was washed with water and dried to give an isomeric mixture of the Diels-Alder adducts (161 mg, $0.52 \mathrm{mmol}, 100 \%$ yield) as a brown solid.

A solution of the isomeric mixture $(150 \mathrm{mg}, 0.49 \mathrm{mmol})$ in dioxane $(16 \mathrm{~mL})$ was refluxed for $48 \mathrm{~h}$ in the presence of trifluoroacetic acid $(2.2 \mathrm{~mL})$. After evaporation, EtOAc was added to the residue. The mixture was filtered off to give 14 (75 mg, $0.24 \mathrm{mmol}, 46 \%$ yield) as a brown solid.

$\mathrm{Mp}>300^{\circ} \mathrm{C}$. IR $(\mathrm{KBr}) \nu_{\mathrm{C}=\mathrm{O}} 1719,1770 \mathrm{~cm}^{-1}, \nu_{\mathrm{NH}} 3100-$ $3550 \mathrm{~cm}^{-1}$. HRMS (ESI+) $[\mathrm{M}+\mathrm{Na}]^{+}$calcd for $\mathrm{C}_{17} \mathrm{H}_{11} \mathrm{~N}_{3} \mathrm{O}_{3} \mathrm{Na} 328.0698$, found 328.0681 .

${ }^{1} \mathrm{H}$ NMR (400 MHz, DMSO- $\left.d_{6}\right): 5.01(2 \mathrm{H}, \mathrm{s}), 7.45$ (1H, d, $J=8.5 \mathrm{~Hz}), 7.66(1 \mathrm{H}, \mathrm{d}, J=8.0 \mathrm{~Hz}), 7.92(1 \mathrm{H}, \mathrm{s}), 8.76(1 \mathrm{H}$, $\mathrm{s}, \mathrm{NH}), 11.18(1 \mathrm{H}, \mathrm{s}, \mathrm{NH}), 12.34(1 \mathrm{H}, \mathrm{s}, \mathrm{NH})$.
Due to its insolubility, the ${ }^{13} \mathrm{C}$ NMR spectrum could not be recorded.

4.4.25. 10-Benzyloxy- $2 H, 5 H, 7 H-1,3,3 \mathrm{a}, 3 \mathrm{~b}, 4,6,6 \mathrm{a}, 11 \mathrm{c}-\mathrm{oc}-$ tahydro-dipyrrolo[3,4- $a: 3,4-c]$ carbazole-3,4,6-trione (15). A mixture of $\mathbf{5 c}(90 \mathrm{mg}, 0.28 \mathrm{mmol})$ and maleimide (34 $\mathrm{mg}, 0.35 \mathrm{mmol})$ in xylene $(7 \mathrm{~mL})$ was refluxed for $48 \mathrm{~h}$. After filtration, the solid was washed with water and dried to give 15 (102 $\mathrm{mg}, 0.26 \mathrm{mmol}, 91 \%$ yield) as a brown-orange solid.

$\mathrm{Mp}>300^{\circ} \mathrm{C}$. IR $(\mathrm{KBr}) \nu_{\mathrm{C}=\mathrm{O}} 1719,1778 \mathrm{~cm}^{-1}, \nu_{\mathrm{NH}} 3100-$ $3550 \mathrm{~cm}^{-1}$. HRMS (ESI+) $[\mathrm{M}+\mathrm{H}]^{+}$calcd for $\mathrm{C}_{23} \mathrm{H}_{18} \mathrm{~N}_{3} \mathrm{O}_{4}$ 400.1297 , found 400.1285 .

${ }^{1} \mathrm{H}$ NMR (400 MHz, DMSO- $\left.d_{6}\right): 4.33-4.39(2 \mathrm{H}, \mathrm{m}), 4.59$ $(1 \mathrm{H}, \mathrm{d}, J=11.0 \mathrm{~Hz}), 4.64(1 \mathrm{H}, \mathrm{d}, J=17.5 \mathrm{~Hz}), 5.16(2 \mathrm{H}, \mathrm{s})$, $6.89\left(1 \mathrm{H}, \quad \mathrm{dd}, \quad J_{1}=9.0 \mathrm{~Hz}, J_{2}=2.0 \mathrm{~Hz}\right), 7.13(1 \mathrm{H}, \mathrm{d}$, $J=2.0 \mathrm{~Hz}), 7.36-7.52(6 \mathrm{H}, \mathrm{m}), 7.97(1 \mathrm{H}, \mathrm{s}, \mathrm{NH}), 11.72$ $(1 \mathrm{H}, \mathrm{s}, \mathrm{NH}), 11.73(1 \mathrm{H}, \mathrm{s}, \mathrm{NH})$.

${ }^{13} \mathrm{C}$ NMR (100 MHz, DMSO- $\left.d_{6}\right): 45.2,69.6\left(\mathrm{CH}_{2}\right), 42.3$, $46.7(\mathrm{CH}), 102.4,111.2,113.1,127.6(2 \mathrm{C}), 127.7,128.3$ (2C) (C tert), 105.2, 115.7, 123.1, 132.1, 133.0, 137.4, 148.3, 153.4 (C quat), 172.3, 177.3, 177.5 (CO).

4.4.26. 10-Benzyloxy-2H,5H,7H-1,3,4,6-tetrahydrodipyrrolo[3,4- $a: 3,4-c]$ carbazole-3,4,6-trione (16). A mixture of compound $15(50 \mathrm{mg}, 0.12 \mathrm{mmol})$ and DDQ $(28 \mathrm{mg}, 0.12 \mathrm{mmol})$ in dioxane $(5 \mathrm{~mL})$ was stirred overnight. After removal of the solvent, the residue was washed successively with water, EtOAc, and small amounts of THF. Compound 16 (19 mg, $0.05 \mathrm{mmol}, 40 \%$ yield) was isolated as a brown solid.

$\mathrm{Mp}>300{ }^{\circ} \mathrm{C}$. IR $(\mathrm{KBr}) \nu_{\mathrm{C}=\mathrm{C}} 1617 \mathrm{~cm}^{-1}, \nu_{\mathrm{C}=\mathrm{O}} 1722$, $1774 \mathrm{~cm}^{-1}, \nu_{\mathrm{NH}} 3100-3500 \mathrm{~cm}^{-1}$. Mass (ESI+) $[\mathrm{M}+\mathrm{H}]^{+}$ 398. HRMS (ESI+) $[\mathrm{M}+\mathrm{Na}]^{+}$calcd for $\mathrm{C}_{23} \mathrm{H}_{15} \mathrm{~N}_{3} \mathrm{O}_{4} \mathrm{Na}$ 420.0960 , found 420.0955 .

${ }^{1} \mathrm{H}$ NMR (400 MHz, DMSO- $\left.d_{6}\right): 5.03(2 \mathrm{H}, \mathrm{s}), 5.29(2 \mathrm{H}, \mathrm{s})$, 7.36-7.70 $(8 \mathrm{H}, \mathrm{m}), 8.79(1 \mathrm{H}, \mathrm{s}, \mathrm{NH}), 11.19(1 \mathrm{H}, \mathrm{s}, \mathrm{NH})$, $12.33(1 \mathrm{H}, \mathrm{s}, \mathrm{NH})$.

Due to its insolubility, the ${ }^{13} \mathrm{C}$ NMR spectrum could not be recorded.

4.4.27. 10-Hydroxy-2H,5H,7H-1,3,3b,4,6,6a-hexahydrodipyrrolo[3,4- $a: 3,4-c]$ carbazole-3,4,6-trione (17). A mixture of $5 \mathbf{d}(120 \mathrm{mg}, 0.52 \mathrm{mmol})$ and maleimide $(61 \mathrm{mg}$, $0.62 \mathrm{mmol})$ in xylene $(14 \mathrm{~mL})$ was refluxed for $48 \mathrm{~h}$. After filtration, the solid was washed with water and dried to give 17 (129 mg, $0.42 \mathrm{mmol}, 81 \%$ yield) as an off-white solid.

$\mathrm{Mp}>300^{\circ} \mathrm{C}$. IR $(\mathrm{KBr}) \nu_{\mathrm{C}=\mathrm{O}} 1708,1778 \mathrm{~cm}^{-1}, \nu_{\mathrm{NH}, \mathrm{OH}}$ $3200-3550 \mathrm{~cm}^{-1}$. Mass (ESI+) $[\mathrm{M}+\mathrm{H}]^{+} 310,[\mathrm{M}+\mathrm{Na}]^{+}$ 332. HRMS (ESI+) $[\mathrm{M}+\mathrm{Na}]^{+}$calcd for $\mathrm{C}_{16} \mathrm{H}_{11} \mathrm{~N}_{3} \mathrm{O}_{4} \mathrm{Na}$ 332.0647 , found 332.0664 .

${ }^{1} \mathrm{H}$ NMR (400 MHz, DMSO- $\left.d_{6}\right): 4.32(1 \mathrm{H}, \mathrm{d}, J=18.0 \mathrm{~Hz})$, $4.36(1 \mathrm{H}, \mathrm{d}, J=11.0 \mathrm{~Hz}), 4.54(1 \mathrm{H}, \mathrm{d}, J=19.0 \mathrm{~Hz}), 4.57$ $(1 \mathrm{H}, \mathrm{d}, J=11.0 \mathrm{~Hz}), 6.69\left(1 \mathrm{H}, \mathrm{dd}, J_{1}=9.0 \mathrm{~Hz}, J_{2}=2.0 \mathrm{~Hz}\right)$, 
$6.84(1 \mathrm{H}, \mathrm{d}, J=2.0 \mathrm{~Hz}), 7.29(1 \mathrm{H}, \mathrm{d}, J=9.0 \mathrm{~Hz}), 7.88(1 \mathrm{H}, \mathrm{s}$, $\mathrm{NH}), 8.96(1 \mathrm{H}, \mathrm{s}), 11.57(1 \mathrm{H}, \mathrm{s}, \mathrm{NH}), 11.71(1 \mathrm{H}, \mathrm{s}, \mathrm{NH})$.

Due to its insolubility, the ${ }^{13} \mathrm{C}$ NMR spectrum could not be recorded.

\subsection{Chk1 inhibitory assays}

Human Chk1 full-length enzyme with an N-terminal GST sequence was either purchased from Upstate Biochemicals (No. 14-346) or purified from extracts of Sf9 cells infected with a baculovirus encoding GST-Chk1. Assays for compound testing were based upon the method described by Davies et al. ${ }^{28}$

\subsection{Growth inhibition assays}

Tumor cells were provided by American Type Culture Collection (Frederik, MD, USA). They were cultivated in RPMI 1640 medium (Life Science technologies, Cergy-Pontoise, France) supplemented with $10 \%$ fetal calf serum, $2 \mathrm{mM}$ L-glutamine, $100 \mathrm{units} / \mathrm{mL}$ penicillin, $100 \mu \mathrm{g} / \mathrm{mL}$ streptomycin, and $10 \mathrm{mM}$ HEPES buffer $(\mathrm{pH}=7.4)$. Cytotoxicity was measured by the microculture tetrazolium assay as described. ${ }^{29}$ Cells were continuously exposed to graded concentrations of the compounds for four doubling times, then $15 \mu \mathrm{L}$ of $5 \mathrm{mg} / \mathrm{mL}$ 3-(4,5-dimethylthiazol-2-yl)-2,5diphenyltetrazolium bromide was added to each well and the plates were incubated for $4 \mathrm{~h}$ at $37^{\circ} \mathrm{C}$. The medium was then aspirated and the formazan solubilized by $100 \mu \mathrm{L}$ of DMSO. Results are expressed as $\mathrm{IC}_{50}$, concentration, which reduced by $50 \%$ the optical density of treated cells with respect to untreated controls.

\section{Acknowledgements}

The authors are grateful to Bertrand Légeret, University Blaise Pascal, Clermont-Ferrand, for recording the mass spectra.

\section{References and notes}

1. Prudhomme, M. Curr. Pharm. Des. 1997, 3, 265-290.

2. Prudhomme, M. Curr. Med. Chem.: Anti-Cancer Agents 2004, $4,509-521$.

3. Knölker, H.-J.; Reddy, K. R. Chem. Rev. 2002, 102, 4303 4427.

4. Anderson, H. J.; Andersen, R. J.; Roberge, M. Progress in the Cell Cycle Research; Meijer, L., Jézéquel, A., Roberge, M., Eds.; Editions: Roscoff, France, 2003; Vol. 5, pp 423-430.
5. Roberge, M.; Berlinck, R. G. S.; Xu, L.; Anderson, H. J.; Lim, L. Y.; Curman, D.; Stringer, C. M.; Friend, S. H.; Davies, P.; Vincent, I.; Haggarty, S. J.; Kelly, M. T.; Britton, R.; Piers, E.; Andersen, R. J. Cancer Res. 1998, 58, 5701-5706.

6. Busby, E. C.; Leistritz, R. T.; Karnitz, L. M.; Sarkaria, J. N. Cancer Res. 2000, 60, 2108-2112.

7. Jackson, J. R.; Gilmartin, A.; Imburgia, C.; Winkler, J. D.; Marshall, L. A.; Roshak, A. Cancer Res. 2000, 60, 566-572.

8. Vermeulen, K.; Van Bockstaele, D. R.; Berneman, Z. N. Cell Prolif. 2003, 36, 131-149.

9. Cuddihy, A. R.; O'Connell, M. J. Cytology 2003, 222, 99-140.

10. McGowan, C. H. Mutat. Res. 2003, 532, 75-84.

11. Bartek, J.; Lukas, J. Cancer Cell 2003, 3, 421-429.

12. Carrassa, L.; Broggini, M.; Erba, E.; Damia, G. Cell Cycle 2004, 3, 1177-1181.

13. Zhao, B.; Bower, M. J.; McDevitt, P. J.; Zhao, H.; Davis, S. T.; Johanson, K. O.; Green, S. M.; Concha, N. O.; Zhou, B. B. S. J. Biol. Chem. 2002, 277, 46609-46615.

14. Jiang, X.; Zhao, B.; Britton, R.; Lim, L. Y.; Leong, D.; Sanghera, J. S.; Zhou, B.-B. S.; Piers, E.; Andersen, R. J.; Roberge, M. Mol. Cancer Ther. 2004, 3, 1221-1227.

15. Berlinck, R. G. S.; Britton, R.; Piers, E.; Lim, L.; Roberge, M.; Moreira da Rocha, R.; Andersen, R. J. J. Org. Chem. 1998, 63, 9850-9856.

16. Piers, E.; Britton, R.; Andersen, R. J. J. Org. Chem. 2000, 65, 530-535.

17. Yoshida, T.; Nishiyachi, M.; Nakashima, N.; Murase, M.; Kotani, E. Chem. Pharm. Bull. 2002, 50, 872-876.

18. Yoshida, T.; Nishiyachi, M.; Nakashima, N.; Murase, M.; Kotani, E. Chem. Pharm. Bull. 2003, 51, 209-214.

19. Terpin, A.; Winklhofer, C.; Schumann, S.; Steglich, W. Tetrahedron 1998, 54, 1745-1752.

20. Hugon, B.; Pfeiffer, B.; Renard, P.; Prudhomme, M. Tetrahedron Lett. 2003, 44, 3927-3930.

21. Hugon, B.; Pfeiffer, B.; Renard, P.; Prudhomme, M. Tetrahedron Lett. 2003, 44, 4607-4611.

22. Hugon, B.; Pfeiffer, B.; Renard, P.; Prudhomme, M. Tetrahedron Lett. 2003, 44, 3935-3937.

23. Hénon, H.; Messaoudi, S.; Hugon, B.; Anizon, F.; Pfeiffer, B.; Prudhomme, M. Tetrahedron 2005, 61, 5599-5614.

24. Hénon, H.; Anizon, F.; Kucharczyk, N.; Loynel, A.; Casara, P.; Pfeiffer, B.; Prudhomme, M. Synthesis 2006, 711-715.

25. Mase, N.; Nishi, T.; Hiyoshi, M.; Ichihara, K.; Bessho, J.; Yoda, H.; Takabe, K. J. Chem. Soc., Perkin Trans. 1 2002, 707-709.

26. Bergman, J.; Janosik, T.; Koch, E.; Pelcman, B. J. Chem. Soc., Perkin Trans. 1 2000, 2615-2621.

27. Hénon, H.; Anizon, F.; Golsteyn, R. M.; Léonce, S.; Hofmann, R.; Pfeiffer, B.; Prudhomme, M. Bioorg. Med. Chem. 2006, 14, 3825-3834.

28. Davies, S. P.; Reddy, H.; Caivano, M.; Cohen, P. Biochem. J. 2000, 351, 95-105.

29. Léonce, S.; Pérez, V.; Casabianca-Pignède, M. R.; Anstett, M.; Bisagni, E.; Atassi, G. Invest. New Drugs 1996, 14, 169-180. 